Cómo citar este trabajo: Calle Vaquero, M. de la. (2019). Turistificación de centros urbanos: clarificando el debate. Boletín de la Asociación de Geógrafos Españoles, 83, 2829, 1-40. http://dx.doi.org/10.21138/bage.2829

\title{
Turistificación de centros urbanos: clarificando el debate
}

Touristification of urban centres: an attempt to clarify the debate

\author{
Manuel de la Calle Vaquero \\ mcalleva@ghis.ucm.es \\ Departamento de Geografía \\ Universidad Complutense de Madrid (España)
}

\section{Resumen}

Las ciudades son destinos turísticos de extraordinario dinamismo. Visitantes y actividades turísticas se concentran en los centros urbanos, sometidos a intensos procesos de turistificación. A partir de revisión bibliográfica, se aborda un estudio de estos procesos atendiendo a sus causas, manifestaciones y efectos sobre la ciudad. El objetivo central del artículo es ayudar a clarificar un debate que ha transcendido el ámbito académico para convertirse en un componente destacado de la agenda urbana contemporánea. A nivel de estado de la cuestión, se identifican puntos de continuidad y de innovación en los estudios sobre el impacto del turismo en la ciudad. Respecto a la naturaleza del fenómeno, se diferencia entre manifestaciones que sólo implican una intensificación de problemas previos y cambios recientes de alcance disruptivo, caso de la proliferación de las viviendas de uso turístico.

Palabras clave: turismo urbano; centros urbanos; turistificación; gentrificación turística; "overtourism".

\begin{abstract}
Cities are extraordinarily dynamic tourist destinations. Visitors and tourist activities are concentrated in urban centres, undergoing intense processes of touristification. Based on a bibliographic review, a study of these processes is undertaken, taking into account their causes, manifestations and effects on
\end{abstract}


the city. The main objective of the article is to attempt to clarify a debate that has transcended the academic sphere to become an outstanding component of the contemporary urban agenda. On the level of the state of the question, points of continuity and innovation are identified in the studies about the impact of tourism in the city. With regard to the nature of the phenomenon, a distinction is made between manifestations that only imply an intensification of previous problems and changes of probable disruptive scope, such as the proliferation of housing for tourist use.

Key words: urban tourism; urban centres; touristification; tourism gentrification; overtourism.

\section{Presentación}

Las ciudades son destinos turísticos muy antiguos, con localidades que llevan recibiendo visitantes de forma interrumpida desde las primeras décadas del siglo XIX. Ocuparon posiciones de primer orden durante el turismo de alta sociedad, quedaron parcialmente eclipsadas con el desarrollo del turismo de masas de sol y playa, y resurgieron con fuerza en la década de los noventa del siglo pasado. En la actualidad son lugares de visita muy populares, en algunos casos destinos de turismo de masas.

Dentro de las ciudades europeas, la actividad turística tiende a concentrarse en los centros urbanos, en general espacios de notable raigambre histórica y valores patrimoniales. Como consecuencia, estos espacios han estado sometidos a un intenso y prolongado proceso de turistificación. Este proceso implica una transformación funcional del espacio, con proliferación de las actividades vinculadas directa o indirectamente al consumo de los visitantes. Como señalaba Knafou (1996), la turistificación puede estar inducida por los turistas y sus prácticas, las empresas y el mercado, y/o los gestores territoriales, en este caso urbanos. El alcance de esta transformación varía en función de la magnitud de la actividad turística, las características específicas de cada centro y la capacidad de los gobiernos locales para encarar esta situación. El turismo puede ayudar a mejorar estos centros pero también puede ser un vector de transformación negativa que amenace su propia condición urbana.

Durante los últimos años se asiste a un crecimiento acelerado de la afluencia de visitantes y la aparición de una serie de fenómenos de alcance todavía incierto, como el uso turístico del parque de viviendas. Como consecuencia, el debate sobre la turistificación y sus efectos ha desbordado los círculos académicos $y$, en algunos destinos y colectivos, se ha impuesto una visión tremendamente negativa. Medios de comunicación de masas y movimientos sociales utilizan indistintamente los términos de turistificación, gentrificación, saturación turística o "overtourism". Este discurso está alentado por corrientes académicas de corte crítico, con una fuerte orientación al activismo. En el orden local, los partidos políticos se posicionan e incluso se llegan a adoptar medidas de gobierno. Y las gremiales del 
turismo salen en defensa de sus intereses, muchas veces contrapuestos en función de los sectores que representan. El turismo, la turistificación y la turismofobia están en la agenda.

El objetivo de este artículo consiste en ayudar a clarificar el debate actual sobre la relación entre turismo y ciudad, un debate muy enmarañado en que se anteponen miradas ideológicas e intereses sectoriales a una reflexión académica genuina, se confunden causas y efectos, no se diferencia entre dinámicas turísticas y dinámicas urbanas y, en ocasiones, prima el marketing académico sobre un avance real del conocimiento.

Como se ha señalado, el foco del artículo se pone sobre los procesos de turistificación y sus efectos a nivel de centros urbanos. Para ello, se organiza el texto en tres grandes partes. La primera aborda el estado de la cuestión sobre los estudios del impacto del turismo en la ciudad, desde la década de 1990 hasta el momento actual. La producción científica en la materia es abundante y se trata sobre todo de clarificar qué aportan nuevas miradas no ancladas en las líneas convencionales. La segunda parte aborda un análisis en detalle de la turistificación a nivel urbano. Se recurre a la técnica del árbol de problemas, que identifica un problema central, sus causas y sus efectos. A efectos de una exposición más legible, se empieza señalando las causas de la reciente ola de turistificación. En términos de investigación, el problema central alude al proceso de turistificación, un fenómeno que presenta una variedad muy notable de manifestaciones a nivel de centros urbanos. A continuación se señalan los principales efectos sobre dichos centros, en concreto los impactos más negativos que suponen una amenaza potencial para la salvaguarda de estos espacios. Por último, la tercera parte del artículo plantea las reflexiones finales. La referencia del texto corresponde a las ciudades españolas, cuyos centros integran distintos paisajes urbanos históricos. No obstante, se adopta una perspectiva más amplia, fundamentalmente de ámbito europeo. A nivel disciplinar, se enfatiza las contribuciones desde la Geografía, aunque se señalan aportaciones de otras ciencias que están contribuyendo a un avance de los estudios urbanos y/o turísticos.

\section{Los estudios sobre el impacto del turismo en la ciudad: contextos, continuidades e innovaciones}

La década de los noventa del siglo XX supone el resurgimiento del turismo urbano. El flujo de visitantes a las ciudades se incrementa, el turismo empieza a hacerse un hueco en la agenda política urbana y, en paralelo, desde diferentes disciplinas se pone la mirada en el turismo de ciudad. Son los años de elaboración de grandes obras de referencia (Cazes \& Potier, 1996; Law, 1993; Page, 1995), con una aportación significativa de la Geografía. Se aborda una primera reflexión sistemática entre turismo y ciudad y se plantea un modelo de análisis del fenómeno a partir de cinco grandes temas: los recursos 
turísticos de la ciudad, la demanda/afluencia de visitantes, la oferta turística, los efectos del turismo a nivel urbano, y el manejo público de la actividad (planificación y gestión). A nivel más específico, destacan las reflexiones de Ashworth y Tundbridge (1990) sobre la "ciudad histórico-turística" y los trabajos de Pearce (1998-1999) sobre las escalas del turismo urbano. Temas y enfoques se introducen rápidamente en la geografía española. En Madrid, un grupo articulado en torno a Troitiño indaga sobre la relación entre turismo y patrimonio en las ciudades históricas (1995, 1998). En Extremadura, Campesino (1999) mantiene una línea similar, de base en la geografía urbana y orientada al planeamiento urbanístico. Destacan también las aportaciones de Zárate (1995), Valenzuela (1992, 1999) y López Palomeque (1995), estos dos últimos mucho más centradas en el turismo de grandes centros metropolitanos.

En estos trabajos se asume la turistificación de las ciudades como el proceso de cambio inherente al nacimiento y desarrollo de la actividad turística en estos espacios. Este proceso tiene distintos efectos a nivel de la ciudad, que se identifican y evalúan en el marco de las reflexiones más generales sobre el impacto turístico, con referencia en el modelo propuesto por Mathieson y Wall (1982). Se asocia impactos a efectos, entendidos como la transformación que deriva de la implantación del turismo en un lugar. Esta transformación viene determinada por el volumen y características de la afluencia de visitantes y, de otra parte, por las condiciones de este lugar, en este caso la ciudad. Estos efectos e impactos tienen distintas dimensiones: económicas, socio-culturales y físico-ambientales. Aunque el discurso de las instituciones se centra en los efectos positivos del turismo, se desarrolla una línea de reflexión académica que señala ventajas e inconvenientes, en especial en las ciudades del arte (Van der Borg et al., 1996; Glasson, 1994). Se adopta el concepto de capacidad de carga (Glasson et al., 1995; García, 2000, 2003), límite difuso a partir del cual la afluencia de visitantes deja más problemas que beneficios. Jansen-Verbeke (1998) aborda el proceso de "tourismification", un proceso de cambio irreversible que afecta a formas y funciones de las ciudades históricas. Poco después, Calle (2002) reflexiona sobre las diferentes situaciones de turistificación en determinados sectores de Granada y Toledo.

En la primera década del siglo XXI el turismo urbano es un fenómeno totalmente consolidado. De las obras generales se pasa a elaborar trabajos muchos más específicos (Ashworth \& Page, 2011). De otra parte, dentro de los estudios urbanos se incorpora el turismo como un vector central de transformación de la ciudad contemporánea. A partir de reflexiones previas sobre la "ciudad turística" (Judd \& Fainstein, 1999), se aborda cuestiones relativas al despliegue espacial del turismo en el espacio urbano (Judd, 2003), a veces planteado en términos de creación de distritos o enclaves turísticos (Hallyar et al., 2008). Se indaga sobre aspectos concretos como la gestión del turismo urbano, el perfil de los 
visitantes o las infraestructuras de transporte. Y también se atisban las posibilidades que empezaban a ofrecer los datos capturados a través de dispositivos móviles y tratamiento mediante SIG (Shoval \& Isaacson, 2007).

En este marco, son frecuentes las referencias al impacto del turismo en la ciudad, ya sea en forma de trabajos monográfico o como aportaciones específicas dentro de documentos más amplios. Russo (2002) analiza el "círculo vicioso" del desarrollo turístico en las grandes ciudades patrimoniales, caso de Venecia. Evans (2002) recoge los discursos de distintos "stakeholders" del distrito histórico de Quebec, espacio que reconoce sometido a procesos simultáneos de gentrificación y turistificación. En su trabajo sobre Nueva Orleans, Gotham (2005) alude, por primera vez, a la gentrificación turística.

A nivel español, en estos años se incrementa de forma sustancial la producción en materia de turismo y ciudad, con una notable apertura temática y disciplinar. Hay aportaciones de orden general, en unas ocasiones centradas en casos específicos (Zárate, 2007; Martos, 2012) y en otras con referencia a la etiqueta de Patrimonio de la Humanidad (Almeida, 2007; Troitiño \& Troitiño, 2009; Ortega \& Such, 2013). De forma más específica, se profundizó en cuestiones como las imágenes turísticas (Donarie \& Galí, 2011; López \& Pazos, 2009); la afluencia y perfil de los visitantes (Molina et al., 2007; Cordente et al., 2011); el significado turístico de los grandes referentes de la ciudad (Manero, 2011; Santos \& Pena, 2014); las relaciones entre paisaje urbano y turismo (Zárate, 2012); el uso que hacen los visitantes de la ciudad (Donaire \& Gali, 2008); el despliegue espacial de la actividad turística en grandes destinos metropolitanos (Barrado, 2010); el impacto económico de los grandes eventos (Herrero et al., 2004); o la génesis turística de ciertos espacios y su conversión en "parques temáticos" (Cócola, 2011).

Desde el resurgimiento del turismo urbano en los años noventa, se ha debatido a nivel académico sobre las ventajas e inconvenientes del turismo. Recientemente este debate ha superado los círculos académicos e institucionales convencionales y se tiende a imponer una imagen negativa. El turismo ha dejado de ser una oportunidad para convertirse en un problema. Este planteamiento está presente en medios de comunicación, movimientos sociales e incluso algunos gobiernos municipales. Y la situación alarma a las gremiales del sector y los organismos nacionales e internacionales del turismo. A nivel de reflexión académica, este nuevo escenario enlaza con dos corrientes o aproximaciones que parten de supuestos distintos para analizar e interpretar el fenómeno: la gentrificación turística y el "overtourism" o sobrecarga turística.

Surgido en el marco de los estudios críticos, el concepto de gentrificación es de enorme popularidad en las disciplinas que atienden a la ciudad. En su formulación original, alude al proceso de sustitución 
de las clases trabajadores por clases medias y altas que afectaba al centro de algunas ciudades, fundamentalmente anglosajonas. Como se ha señalado antes, Gotham (2005) utiliza por primera vez el término de gentrificación turística, con un desplazamiento de la población originaria también presionada por la proliferación de lugares de entretenimiento y otros vinculados más o menos al turismo. Pronto este planteamiento se hace muy popular entre algunos estudiosos de lo urbano, también en relación a las ciudades españolas (García et al., 2007; Morell, 2009). Así, un conjunto amplio de reflexiones surgidas en el ámbito de la gentrificación empiezan a incorporar el tema del turismo desde una perspectiva crítica, con un amplio espectro de intereses (Sequera \& Nofre, 2018): las tensiones en el mercado local del alojamiento, con desplazamiento de los vecinos de menos ingresos; la desposesión simbólica y el extrañamiento respecto a espacios que devienen en mercancía turística; la marginalización y criminalización de actividades que las autoridades entienden como inconvenientes para el éxito turístico; la expulsión del comercio de proximidad debido a la expansión de actividades turísticas y de entretenimiento, caso del ocio nocturno; o las políticas urbanas que favorecen la gentrificación turística a costa de la población local.

El desplazamiento es uno de los argumentos centrales de esta línea de trabajo. Implica sustitución en el espacio de grupos sociales, con traslados de las clases con menor poder adquisitivo a zonas más periféricas. Pero este argumento presenta una debilidad: el vector que impulsa el desplazamiento es la llegada creciente de turistas y el desplazamiento, si se produce, puede afectar a todos los grupos sociales. Hiernaux y González (2014) resuelven esta incongruencia mediante la consideración del turista como un habitante más del centro histórico, un miembro genuino de una clase media global que expulsa al habitante tradicional de los centros de las ciudades de Latinoamérica. De forma similar, Sorando y Ardura (2018) señalan la emergencia de una gentrificación 4.0 donde la población residente se sustituye por una no-población, entendida como una población muy móvil y sin vínculos de permanencia con ese espacio.

En cierto sentido, se adopta una visión totalizadora que llega a asociar gentrificación y cambio urbano. Y se asume una visión de los centros históricos como paraísos de vida comunitaria amenazados por las fuerzas del capital y las instituciones de gobierno a diferentes niveles. Especialmente en las ciudades del sur de Europa, se hace equivaler gentrificación con gentrificación turística y ésta con turistificación, ignorando que algunas de estas ciudades son destinos turísticos desde hace dos siglos y que existe un debate científico sobre los efectos del turismo en las ciudades que dura ya tres décadas. Dentro de las corrientes críticas, sólo recientemente han aparecido voces que señalan las diferencias entre los procesos de gentrificación y turistificación (Sequera \& Nofre, 2018). No cabe duda de que ambos fenómenos están relacionadas, pero más en los orígenes de la transformación (un nuevo ciclo de 
valorización de los centros de algunas ciudades) que en sus efectos, ya que ambos procesos pueden reforzarse pero también excluirse. Así ocurre cuando la propia presión turística acaba expulsando a los grupos sociales protagonistas de la primera gentrificación residencial.

En paralelo a la eclosión de los estudios sobre gentrificación turística ha surgido otra línea de trabajo centrada en el "overtourism", que suele traducirse como "sobreturismo" o más exactamente saturación o sobrecarga turística. Si bien este término empieza a utilizarse hace años, su uso se generaliza en tiempos recientes, asociado a los problemas que genera el turismo en una serie de destinos muy renombrados: Ámsterdam, Barcelona, Dubronik y Venecia, entre otros. En su acepción más sencilla, se entiende que existe "overtourism" cuando el turismo genera más inconvenientes que beneficios para las ciudades donde está presente. En este sentido, corresponde a una línea de reflexión consolidada en el ámbito de los estudios turísticos, en especial en los trabajos centrados en la sostenibilidad y su aplicación a través de los planteamientos de la capacidad de carga y los límites del cambio aceptable (Koens et al., 2018). Así, la novedad no reside tanto en el objeto de estudio sino en la popularización mediática del término y su uso reciente en ciudades de larga tradición turística donde los actores locales no reconocían problemas de este tipo.

La idea de sobrecarga turística es de uso frecuente en el discurso oficial de las entidades del turismo. De acuerdo a sus planteamientos, no se trata tanto de demonizar el turismo como de abordar una gestión exitosa del éxito turístico de muchas ciudades, una gestión que minimice los efectos negativos al tiempo que aprovecha las posibilidades que supone el turismo para el bienestar urbano. Esta posición se plasma en un conjunto amplio de documentos de entidades que operan a diferente escala: la Organización Mundial del Turismo (WTO, 2018 y 2019), el World Travel \& Tourism Council (2017), el Parlamento Europeo (Peeters et al., 2018), la red de DMOs European Cities Marketing (2018) y, a nivel nacional, organizaciones como la Austrian Hotelier Association (2018). Las referencias a un nuevo modelo de gobierno y gobernanza urbana son una constante, siempre con participación de las partes interesadas e incluso liderazgo de ciertos grupos de interés.

La sobrecarga turística se asocia a los efectos más negativos de la turistificación. En todos estos trabajos se presta especial atención a la medición del fenómeno, a efectos de dotar a los gestores turísticos de una serie de indicadores que permitan identificar situaciones de riesgo de "overtourism" y establecer comparaciones entre destinos. Estos indicadores son de diferente tipo. En unos casos simplemente reflejan la dinámica de la afluencia turística: crecimiento del número de pernoctaciones, distribución temporal de la afluencia, etc. En otros, relacionan variables turísticas con datos de orden local: peso del turismo en la economía y el empleo del destino, visitantes o pernoctaciones por superficie o por el 
número de residentes, etc. Se suele recurrir a las fuentes estadísticas convencionales, aunque crece el uso de técnicas de minería de datos para extraer información de plataformas como TripAdvisor, Booking y Airbnb. El problema de estos indicadores, ya planteado en los estudios de capacidad de carga, es que reflejan niveles de crecimiento, densidad, intensidad... turística, pero no situaciones de "overtourism". Estas situaciones parecen responder más a un estado de opinión negativo hacia el turismo, por lo que se hace necesario complementar las aproximaciones más cuantitativas con estudios sobre la percepción de la comunidad sobre las ventajas e inconvenientes del turismo en su territorio. Estudios generales y trabajos más específicos sobre las posiciones de los "stakeholders" turísticos más tradicionales así como de otros actores con nuevos discursos y perspectivas. Estas posiciones pueden ayudar a fijar los umbrales valorativos de las diferentes dimensiones de la capacidad de carga: el momento a partir del cual los inconvenientes del crecimiento turístico superan sus beneficios.

Simplemente a nivel español, el panorama actual de las investigaciones en turismo y ciudad es rico y complejo. Se mantienen aproximaciones tradicionales, que se nutren de aportaciones tanto de la geografía urbana como de la geografía del turismo (véase por ejemplo, los trabajos de López, 2015 y Troitiño \& Troitiño, 2018). De forma paralela, se ha consolidado una línea de trabajo basada en el uso de "big data", extraídos mediante técnicas de minería de datos y tratados con SIG. En general, permiten un mejor conocimiento del despliegue geográfico del turismo urbano (Salas-Olmedo et al., 2018), a partir de la captura y análisis de los recorridos de los visitantes (Galí et al., 2015) o las pautas de implantación de distintas fórmulas de alojamiento (Gutiérrez et al., 2017). Y además existen líneas de cruce muy fructíferas entre enfoques que corresponden a tradiciones investigadoras diferentes. Así, surgen trabajos que se nutren a nivel teórico de los estudios críticos y a nivel técnico de las tradiciones más cuantitativas (Yrigoy, 2018), además con una fuerte orientación hacia el activismo (Mansilla, 2018). De igual forma, se relaciona "overtourism" y malestar urbano, un malestar contra el que elevan sus voces unos movimientos sociales también en proceso de turistificación (al respecto, véase los trabajos de Milano 2018a y 2018b).

\section{Una presión turística creciente: datos, causas, espacios}

La reflexión académica reciente sobre turismo y ciudad se realiza en un contexto de crecimiento de la presión turística. Una forma común de aproximarse a esta presión es el uso de indicadores de intensidad turística. A nivel europeo, TourMIS relaciona pernoctaciones en alojamientos comerciales y población residente, si bien las unidades territoriales de referencia estadística, el año de cómputo de la 
población y los tipos de alojamiento considerados varían según destino. ${ }^{1}$ Teniendo en cuenta estas salvedades, en 2017 las ciudades europeas de mayor intensidad turística fueron Venecia (30,1 pernoctaciones por cada habitante), Lisboa $(24,8)$, Salzburgo $(20,8)$ y Florencia $(19,8)$. Para Roma se maneja una cifra de 9,6 , superior a Berlín $(8,7)$, Viena $(8,2)$, Londres $(6,3)$ y París $(3,8)$.

El uso de este indicador para las ciudades españolas, limitado a los viajeros alojados en hoteles, también refleja altos niveles de intensidad en una amplia variedad de destinos. ${ }^{2}$ La cifra más elevada corresponde al municipio de Palma de Mallorca (21,3 pernoctaciones por residente), seguido por Santiago de Compostela (15), Granada (14), Barcelona (12,2) y Toledo $(10,9)$. En Sevilla se registra una cifra de 7,6, en Donostia-San Sebastián (7), en Madrid (6), en Valencia $(5,1)$ y en Málaga $(4,4)$.

Estos niveles de intensidad turística derivan de un crecimiento muy notable de la afluencia de visitantes. Dado que la actividad turística se concentra sobre determinados sectores de los centros urbanos, el incremento actual de la actividad turística implica necesariamente un fuerte incremento de la presión sobre estos espacios y los consiguientes procesos de turistificación. Y confluye otro vector añadido: la proliferación de las viviendas turísticas, fórmula más barata de alojamiento que además tiende a concentrarse sobre algunos barrios de los espacios centrales. Sobre estos aspectos se reflexiona en los epígrafes siguientes.

\subsection{El crecimiento de la actividad turística y sus causas}

De acuerdo con los datos de TourMIS sobre turistas alojados en hoteles y establecimientos similares, en 2018 las 15 ciudades más visitadas de Europa registraron 362,7 millones de pernoctaciones. Respecto a 2011, año que se incorpora París al sistema, se ha ganado más de 73 millones, un 25,42 \%. A nivel global, se trata de un incremento muy rápido y notable. Y resulta especialmente llamativo que esta cifra haya sido superada por un gran número de destinos: Ámsterdam (73,82\%), Berlín (47\%), Budapest $(57,1 \%)$, Hamburgo (52,46\%), Estambul (73,9\%) o Lisboa (67,6 \%), entre otras.

Esta dinámica de crecimiento se repite en las ciudades españolas. Como referencia, se toman los datos acumulados de los 44 destinos de turismo urbano que ofrece la Encuesta de Ocupación Hotelera (EOH) para el periodo 2007 y 2017. Durante toda la serie, 2009 marca un mínimo de 31,05 millones

1 TourMIS (http://www.tourmis.info) aporta una base de datos sobre afluencia turística de las principales ciudades europeas. Con soporte en la MODUL University Vienna, organiza la información suministrada por las entidades de gestión turística de estas ciudades. También da soporte técnico a los informes de la Euopean Cities Marketing (https://www.europeancitiesmarketing.com).

2 La fuente utilizada es la Encuesta de Ocupación Hotelera del Instituto Nacional de Estadística (http://www.ine.es/dyngs/INEbase/es/operacion. htm?c=Estadistica_C\&cid=1254736177015\&menu=ultiDatos\&i $d p=1254735576863)$. 
de turistas alojados en hoteles, cerca de dos millones menos que antes del inicio de la crisis, en 2007. En cambio, en 2017 se contabilizaron 42,27 millones de turistas, lo que supone un crecimiento respecto al mínimo de 2009 de un 35,59\%. Y este incremento ha sido especialmente intenso en los últimos años, con incrementos interanuales que rondan el $5 \%$. Además se trata de una dinámica que afecta a todo tipo de ciudades, como demuestra que niveles de crecimiento por encima del $50 \%$ se registran en destinos tan dispares como Ávila (56,93\%), Castellón de la Plana (52,66\%), Córdoba (53,52\%), Málaga (79,51\%), Santiago de Compostela (50,05\%), Sevilla (57,08\%) y Zaragoza $(55,28 \%)$.

La expansión de la actividad turística afecta al conjunto de modalidades asociadas al turismo de ciudad. E incluso hay tipologías turísticas que han experimentado una dinámica positiva durante todos los años, siendo escasamente afectadas por la recesión. En 2017, los puertos españoles recibieron la visita de 4.238 cruceros que transportaron 9,3 millones de cruceristas. Respecto a 2007, supuso incrementos del $19,48 \%$ y $84,39 \%$ respectivamente. Barcelona, con 2,7 millones de pasajeros, sigue siendo el primer puerto de Europa, por delante de Civitavecchia (2,2 millones), Southampton (2), Palma $(1,6)$, Marsella (1,5), Venecia (1,4) y El Pireo (1). Desde 2007, el número de pasajeros registrados en Barcelona ha crecido en un 53,6\%, cifra muy elevada pero inferior a otros puertos menos frecuentados como Málaga (34,2\%), Valencia $(174,01 \%)$ y Bilbao $(266,57 \%)$.

Los factores que han favorecido este rapidísimo crecimiento de la afluencia de visitantes se sitúan en los ámbitos de las políticas urbanas, de la dinámica general de la actividad económica y de las estrategias empresariales, sobre todo de las grandes corporaciones. Se trata de un conjunto de procesos complejos e interrelacionados, sin que resulte fácil determinar el vector desencadenante.

El primer vector de turistificación, que no necesariamente el más importante, se sitúa en el ámbito de las políticas urbanas. Desde la década de 1990 estas políticas se orientan al crecimiento económico en un contexto de creciente competencia interurbana. Se reconoce la aportación del turismo a este desarrollo, por lo que las ciudades pugnan por ganar atractivo como lugares de visita. Este atractivo implica la mejora de la calidad ambiental de determinados sectores con operaciones emblemáticas, el desarrollo de grandes eventos y la mejora de las infraestructuras de acceso. En una lógica de empresarialismo urbano, se ha buscado el acuerdo con los grandes operadores privados y se trabaja en el binomio planificación estratégica-grandes proyectos. La ciudad es un producto y, por lo tanto, también requiere de marca y estrategia de comunicación.

Los años de la Recesión reforzaron este enfoque neoliberal. De una parte, el ajuste fiscal limitó la capacidad de los gobiernos locales en movilizar recursos y liderar operaciones, por lo que hizo 
todavía más necesario recurrir a las grandes corporaciones empresariales para el desarrollo de proyectos emblemáticos. De forma paralela, las políticas turísticas adoptaron un enfoque de marketing mucho más marcado. En la práctica, centraron la totalidad de sus esfuerzos en la promoción externa, en un contexto en el que el turismo era uno de los pocos sectores que mantenía sus niveles de actividad. Y se adoptaron toda una serie de medidas liberalizadoras que se tradujeron en facilidades para la implantación de las actividades turísticas, como el cambio en la legislación de los alquileres. Ejemplo palmario es la Golden Visa, mecanismo que permite obtener la residencia a extracomunitarios que acrediten una inversión significativa de capital en el país de recepción. Entre otros procedimientos, se consigue mediante la compra de inmuebles.

El actual proceso de turistificación también deriva de la recuperación económica posterior a la Gran Recesión, que ha sentado las bases para un rápido crecimiento de la demanda turística. De forma convencional, la recesión se asocia a la etapa comprendida entre los años 2008 y 2013. Si se toma como referencia las cifras de turistas alojados en los hoteles de las ciudades españolas, existe una correspondencia perfecta: después de unos años difíciles, en 2014 se alcanza la cifra de turistas del año 2007, en torno a los 18,5 millones. A nivel global, la recuperación de los mercados tradicionales europeos es anterior, pues ya en 2010 se había superado el número de viajeros alojados en hoteles de 2007. E incluso el crecimiento ha sido mucho más intenso, pues se ha pasado de 8,9 millones en 2007 a 8,3 en 2009 y 12,2 en 2017. Respecto a 2007 el crecimiento ha sido del 35,9\% y en relación a 2009 del 45,6\%. Es más, los mercados de larga distancia han registrado dinámicas todavía más positivas, con incrementos del 70,27\% en los viajeros de Estados Unidos desde 2009 y de un $123,89 \%$ en lo que la EOH califica como "resto del mundo" (123,89\%), donde se incluye Rusia y otros mercados emergentes de Asia y América Latina. La creciente presencia de turistas de largas distancias es una constante y en ello influye también una cada vez más importante clase media de algunos de los países en vías de desarrollo que asumen pautas de consumo turístico características de los economías más avanzadas.

El incremento tan notable de la afluencia de visitantes está apoyado en una reducción del coste del viaje turístico, con especial incidencia en los destinos urbanos. En primer lugar, afectó al sector transporte, con la expansión de las compañías de bajo coste. Según los datos de AENA, el número de pasajeros en los aeropuertos españoles pasó de 208,68 millones en 2007 a 248,33 en 2017. El crecimiento, de un 19,01\% se ha producido en los últimos años, ya que hasta 2015 no se recuperaron las cifras de 2007. Y en este crecimiento han tenido especial protagonismo aerolíneas como Ryanair, con 44 millones de pasajeros transportados en 2017, Vueling $(34,7)$ y easyjet $(13,9)$. La participación 
de estas tres compañías en el tráfico aéreo español ha pasado de suponer el 13,5\% en 2007 al $37,34 \%$, aunque con diferencias significativas entre aeropuertos.

Más recientemente, factores como la liberalización de la prestación de algunos servicios a escala europea y la irrupción de las economías de plataforma también han favorecido una reducción del coste asociado a la estancia. La aplicación de la Directiva del Parlamento Europeo y del Consejo (123/2006/CE) relativa a los servicios en el mercado interior, conocida coloquialmente como Bolkestein, ha favorecido la eclosión de los denominados "free tours" por todas las ciudades de Europa. De igual forma la movilidad turística urbana se encuentra en un estado de cambio acelerado debido a la acción directa de empresas como Uber y Cabify. No obstante, el ámbito más afectado ha sido el sector del alojamiento, con la aparición de una oferta creciente de viviendas de uso turístico (VUT) que compite directamente con la hotelería más convencional. El alquiler de este tipo de viviendas ha sido una práctica tradicional en los destinos de sol y playa. La irrupción de Airbnb y otras empresas similares ha favorecido su expansión a los destinos urbanos, donde han supuesto una auténtica disrupción. Estas empresas se basan en plataformas digitales que facilitan el contacto entre detentadores de viviendas y turistas, sin que dichas empresas se reconozcan como canales de intermediación turística. Los propietarios ofertan sus viviendas para el mercado turístico, primero en una lógica de economía colaborativa y progresivamente con una finalidad estrictamente mercantil. La vivienda deviene en producto turístico, ya que la rentabilidad derivada de este uso ocasional es más elevada. El negocio se expande cuando los inversores inmobiliarios invierten directamente en esta fórmula, desde pequeños propietarios-rentistas de ámbito local hasta grandes fondos de inversión que compran inmuebles completos para dedicarlos a este uso. Dado que los precios por unidad de alojamiento son inferiores a los que ofrece el sector hotelero, supone de hecho un factor adicional de impulso al crecimiento de la afluencia turística a las ciudades. Sin embargo, la reciente proliferación de las VUT tiene unas implicaciones a nivel urbano que van mucho más allá de la reducción de costes. Supone un cambio radical en las formas de producción del espacio turístico destinado al alojamiento, que ahora puede hacerse de forma mucho más rápida y flexible vivienda a vivienda y en lugares donde la propia conformación de la trama urbana dificulta la implantación de inmuebles destinados a hoteles.

\section{2 ¿Hacia una nueva geografía turística de la ciudad?}

El crecimiento reciente de la afluencia turística está afectando a diferentes tipos de destinos urbanos, aunque no por igual a todas las ciudades. Atendiendo a las causas señaladas en el apartado anterior, la dinámica más explosiva corresponde a aquellos destinos que: 1. Cuentan con un elevado grado de 
accesibilidad aérea, especialmente en vuelos de bajo coste; 2. Presentan una imagen turística consolidada en mercados externos, sobre todo como lugares con cierto ambiente cultural y diversión garantizada; y 3. Disponen de puerto de cruceros. Cuando se juntan las tres circunstancias la dinámica turística se dispara, como pasa en las grandes ciudades de la costa mediterránea (Barcelona, Palma, Valencia, Málaga, etc.). Dado la creciente dependencia o interdependencia entre destinos de una misma región turística funcional, al final estas dinámicas también afectan a lugares de un entorno amplio, reforzando o modificando procesos mucho más locales.

A escala intraurbana, la presión se concentra sobre determinados sectores de la ciudad. La implantación de la actividad turística sobre el espacio urbano no es homogénea, sino que destaca por su selectividad espacial. En general, estos espacios de concentración de visitantes y actividades turísticas reciben la denominación de distritos turísticos, aunque también se manejan apelativos como recintos turísticos, zonas de especialización turística, enclaves e incluso "burbujas turísticas" (Judd, 1999). Pearce (2001) diferencia seis ámbitos de este tipo, no excluyentes entre sí: distritos históricos, distritos étnicos, espacios sagrados, zonas de remodelación, áreas de entretenimiento y distritos turísticos de negocios. En el caso de las ciudades europeas, los visitantes tienden a concentrarse sobre los centros históricos y, en concreto, en lo que Ashworth \& Tundbridge (1990) denominaron "ciudad histórico turística". Los trabajos de la OMT, basados en entrevistas a los responsables de las administraciones turísticas locales, también han reflejado la primacía de los sectores históricos como atractivos centrales de la ciudad (WTO, 2012).

Estos espacios presentan una larga trayectoria turística y, desde hace mucho tiempo, están afectados por procesos de turistificación más o menos intensos. Es fácil reconocer estos sectores en destinos como Toledo, en un eje que une Zocodover, la Catedral y San Juan de los Reyes; en Segovia, en las calles que conectan el Acueducto, la Catedral y el Alcázar; en Córdoba, en torno a la Mezquita y en la Judería; en Sevilla, también en los aledaños de la Catedral y el Real Alcázar, con el barrio de Santa Cruz; o en Madrid, en las calles centrales del barrio de los Austrias y el eje del Prado. La turistificación de estos espacios es antigua y, si acaso, el reciente crecimiento de la afluencia de visitantes lo único que supone es un reforzamiento de procesos hace tiempo consolidados.

Junto a estos espacios, la reciente ola de turistificación está afectando a barrios centrales aledaños hasta hace poco tiempo ajenos a la presencia de visitantes: Islington en Londres (Maitland \& Newman, 2004), Kreuzberg en Berlín (Füller \& Michel, 2014), Vesterbro y Nørrebro en Copenhage (Stors \& Kagermeier, 2013) o Poblenou en Barcelona (Mansilla, 2018). Esta ampliación de la huella turística más allá del "beaten track" está impulsada por un conjunto de factores que tienden a retroalimentarse. En 
primer lugar, se señala la emergencia de un nuevo turista que pretende un contacto diferente con la ciudad, un contacto más auténtico con la vida diaria (Matiland, 2010) alejado de las burbujas turísticas establecidas hace tiempo. Se trata de un visitante cosmopolita, de un estilo de vida internacional, con pautas de consumo "hipster" comunes a muchos gentrificadores urbanos (por ejemplo, el uso de la bicicleta). De hecho, este visitante pretende una mayor aproximación a la vida local, buscando situarse expresamente en una esfera simbólica opuesta al turista más convencional.

La búsqueda de la diferenciación también supone cierto rechazo a la industria turística tradicional. Se recurre así a diferentes fórmulas de la economía colaborativa (Romero, 2018), como los recorridos guiados a cargo de voluntarios locales o las distintas fórmulas de alojamiento compartido. Como ha sucedido en otros ámbitos de actividad, al final estas fórmulas se han ido mercantilizando y son el núcleo de negocio de una serie de empresas de plataforma como Couchsurfing, HomeAway, 9fltas, FlipKey o la archiconocida Airbnb. Resulta muy significativo que algunas de estas empresas no se reconozcan como operadores turísticos, sino como plataformas digitales que simplemente ponen en contacto a viajeros y anfitriones. De igual forma, resaltan que favorecen un contacto del turista mucho más cercano con la ciudad y sus habitantes, así como una mayor derrama económica de la actividad turística sobre el entramado comercial y hostelero local. Más allá de su discurso publicitario, a nivel urbano destaca sobre todo su concentración en los nuevos frentes de turistificación, aquellos barrios donde la presencia de visitantes ha sido hasta hace poco tiempo marginal. La transformación de una vivienda en una vivienda de uso turístico es un proceso muy sencillo, sobre todo en ausencia de un marco regulatorio estricto. Y el diferencial de rentas entre uso residencial y alojamiento turístico del parque de viviendas es todavía más elevado en estos barrios, ya que siguen manteniendo un fuerte componente residencial.

Además estos espacios han sido objeto de atención preferente por parte de las administraciones públicas, desde diferentes esferas de actuación. Planes y programas de regeneración urbana han impulsado la mejora tanto de la calidad ambiental como del paisaje urbano. Esta mejoría se ha traducido en un incremento del atractivo residencial, que favorece la gentrificación, pero también del atractivo turístico. Como se ha señalado respecto a la preservación histórica en las ciudades de Estados Unidos (Bures \& Cain, 2008), ciertas formas de patrimonialización llevan implícitamente aparejadas crecimiento de las actividades turísticas. Dentro de las políticas urbanas, este crecimiento puede ser un objetivo explícito, implícito, sobrevenido e incluso no deseado. En cambio, es un componente destacado de la estrategia turística reciente de muchas ciudades. En Barcelona, el Plan Estratégico de Turismo 2010-2015 planteaba la necesidad de desconcentrar el turismo (López, 2015; Milano, 2018b). En Madrid, el Plan 2012-2015 establecía un programa de actuación de base territorial 
denominado "Madrid Plays Off" centrado sobre tres espacios: Ejes Fuencarral-Chueca-Triball, OffPaseo del Arte (Matadero Madrid, Casa Encendida), y Barrios de Embajadores y Lavapiés. A diferencia de Barcelona, la expansión de la zona turística tradicional se justificaba no tanto para descongestionar los sectores urbanos más saturados como para incorporar nuevos espacios a la oferta de la ciudad (Calle et al., 2018).

En suma, el vertiginoso crecimiento reciente de la afluencia de visitantes y los cambios asociados al proceso de "airbnbization" (Richards, 2017) están suponiendo cierto cambio en la geografía turística de la ciudad, en especial de sus espacios centrales. De una parte, los sectores de mayor trayectoria turística están sometidos cada vez a una mayor presión. De otra, emergen nuevos frentes de turistificación, barrios hasta hace poco ajenos a la presencia de visitantes que empiezan a poblarse de actividades más o menos relacionados con el turismo. Si la presión creciente sobre los espacios turísticos tradicionales puede provocar su colapso, en el caso de los barrios sometidos a procesos recientes de turistificación se asiste a un proceso de contestación social enmarcado dentro de los movimientos sociales por el derecho a la ciudad.

\section{4 ¿Cómo se manifiesta la turistificación? Presencias, actividades, paisajes}

El proceso de turistificación de los centros urbanos es complejo y multidimensional (Freytag \& Bauder, 2018). En una aproximación general, cabe diferenciar cinco manifestaciones de este proceso: 1. Una mayor presencia de visitantes en los espacios centrales de la ciudad; 2. El incremento de las actividades directamente vinculadas al consumo turístico; 3. La reorientación de una gama cada vez más amplia de negocios a la clientela foránea; 4. La conversión de la vivienda en una nueva mercancía turística; y 5. La creación de un paisaje o escena urbana donde predominan elementos turísticos. En unos casos este proceso de turistificación sólo implica una intensificación de fenómenos de largo recorrido; en otros, responde a mutaciones más recientes de la actividad turística, de alcance todavía incierto.

Desde hace mucho tiempo, turistas y excursionistas son figuras habituales en las ciudades europeas. Los visitantes están presentes en los principales museos y monumentos. Transitan por calles y plazas, a veces en una lógica de disfrute del ambiente urbano y otras sólo como canales que permiten el desplazamiento peatonal entre los principales espacios turísticos del centro. Tienen presencia en los servicios de transporte público. Y sus vehículos ocupan superficie de tránsito rodado y aparcamiento. A nivel general, los visitantes se desplazan más lentos que los usuarios habituales de la ciudad, pueblan las calles en momentos en que estos usuarios están con otros quehaceres, y una parte significativa se desplaza en grupos organizados, por lo que son fáciles de reconocer. Si bien estos rasgos genéricos 
son conocidos, falta todavía ser capaces de determinar su peso dentro del conjunto de personas que utilizan habitualmente los centros urbanos. Sólo un número reducido de museos y monumentos recogen la procedencia de los visitantes, más allá de su condición de nacional o extranjero. Y los estudios de movilidad no suelen discriminar entre componentes turísticos y no turísticos.

Una segunda manifestación de la turistificación consiste en la expansión de las actividades de consumo preferente por los visitantes. El alojamiento convencional constituye el núcleo de estas actividades, ya que la condición tradicional del turista está aparejada a la pernoctación fuera de su entorno habitual. De acuerdo a los datos de la EOH, el número de plazas en hoteles y hostales de las 44 ciudades españolas antes referenciadas ha crecido en un 22,15\% entre 2007 y 2017 (mes de agosto). Este incremento ha sido mucho mayor en alguna de las principales ciudades turísticas del país: 60,44\% en Barcelona, 40,46\% en Málaga, 35,53\% en Donostia-San Sebastián o 34,18\% en Sevilla. Crece la planta de alojamiento comercial y buena parte de este crecimiento tiene lugar en los espacios centrales de la ciudad, de tal forma que el sector del alojamiento es uno de los grandes protagonistas de la dinámica actual de muchos centros urbanos. En algunos casos se trata de implantaciones hoteleras de alta categoría asociadas a operaciones emblemáticas, que muchas veces implican cambio de uso y afectación de edificios dotados de algún grado de protección patrimonial. En otras ocasiones son "hoteles boutique" de menores dimensiones, en general antiguos inmuebles residenciales reconvertidos a este uso. De forma adicional, está creciendo de forma muy significativa el número de edificios de apartamentos para alquiler turístico y de "hostels" o albergues con habitaciones de uso colectivo. En esta "hotelización" del espacio urbano interviene un conjunto amplio de agentes: promotores inmobiliarios; empresas constructoras; fondos de inversión y SOCIMls; entidades financieras; cadenas hoteleras y emprendedores turísticos; y también las administraciones locales. La complejidad de las operaciones se incrementa y se inserta en la lógica del funcionamiento del mercado inmobiliario. Su reciente orientación al alojamiento turístico se basa en unas expectativas de alta rentabilidad, en todo caso superiores a las que se podrían obtener con otros productos de este mercado (oficinas, centros comerciales, viviendas, etc.).

Además del alojamiento convencional, la mayor presencia de visitantes favorece la expansión de otros tipos de negocios orientados preferentemente a turistas y excursionistas. Crece el número de tiendas de recuerdos, desde la joya artesanía más genuina hasta los "souvenirs" de producción fabril y diseño estereotipado. Los establecimientos de cambio de moneda también están presentes. Y proliferan los negocios vinculados a la movilidad turística: de visitas guiadas a pie, de alquiler de bicicletas, patinetes o "segways", o de excursiones radiales a lugares del entorno de la ciudad. 
La tercera manifestación de la turistificación consiste en una progresiva reorientación de las actividades comerciales y hosteleras a la clientela foránea. Estos negocios ofertan productos de consumo orientados a una clientela amplia, desde los vecinos a los turistas internacionales. Es el caso de un bar, una librería, un comercio de alimentos o una tienda de ropa. El proceso de turistificación implica una adaptación progresiva de estos establecimientos hacia los turistas, transformación que afecta a horarios, precios, idiomas de atención e incluso al tipo de productos expuestos. Librerías y quioscos nutren sus mostradores con guías turísticas de la ciudad. Bares y restaurantes ofertan adaptaciones de comidas supuestamente típicas y desarrollan fórmulas de "take away". Las tiendas de alimentación venden fruta por unidades, bocadillos y latas de refrescos. Y los grandes establecimientos comerciales incorporan secciones específicas con vendedores especializados en mercados como el ruso o el chino. En unos casos esta reorientación obedece a una estrategia de los comerciantes y hosteleros hace tiempo asentados, deseosos de aprovechar las oportunidades de negocio de una demanda turística creciente. Los mercados municipales de abastos reflejan bien este cambio (Crespi \& Domínguez, 2016; García, 2017), dentro de un proceso general de "gourmetización" en el que siempre se alude al turismo. En otras ocasiones se trata de nuevas implantaciones que incorporan en su plan de negocio la existencia de una creciente demanda con origen en los turistas. La expansión en los centros urbanos de los establecimientos ligados a las marcas globales (cafeterías, locales de comida, tiendas de ropa, etc.) responde a esta lógica. Y, dado que son marcas fácilmente reconocibles por los visitantes, su penetración en el mercado turístico resulta de suma facilidad.

La conversión de la vivienda en una nueva mercancía turística es una de las manifestaciones más genuinas del proceso actual de turistificación. Tradicionalmente, la generación de espacio para alojamiento turístico era un proceso lento y sometido a un fuerte control administrativo, ya que implicaba la construcción o transformación de inmuebles completos situados en espacios generalmente dotados de afecciones patrimoniales. En la actualidad, crece sobre todo una oferta de viviendas de uso turístico de conformación líquida, de fácil adaptación a las fluctuaciones de la demanda y notable irregularidad en su funcionamiento, lo que hace extremadamente difícil su cuantificación y caracterización. Inside Airbnb ha contabilizado 77096 anuncios de VUT en Londres a fecha de mayo de 2019. En París computa 59 881, en Roma 29 436, en Amsterdam 19619 y en Barcelona 18 302. De los 17301 anuncios en Madrid, 8.918 corresponden a inmuebles situados en el distrito Centro. Los distritos contiguos concentran la mayor parte de la oferta restante: 1139 en Salamanca, 958 en Chamberí, 967 en Arganzuela, 575 en Retiro y 481 en Moncloa-Aravaca, especialmente en torno a Plaza de España-Príncipe Pío. Buena parte de los anuncios corresponden a viviendas completas $(64,7 \%)$, en especial en el distrito Centro (75,9\%). Esta circunstancia, añadida a los altos niveles de 
disponibilidad y la concentración de buena parte de la oferta en manos de unos pocos operadores, distancia esta fórmula de alojamiento de los planteamientos de la economía colaborativa en los que muchas veces se ha arropado. En todo caso está generando la proliferación de nuevos negocios de implantación asociada a los lugares de concentración de las VUT: lavanderías, consignas donde dejar el equipaje en los días que no se dispone del alojamiento, y agencias gestoras del alojamiento y servicios anexos (reparaciones, limpieza, etc.).

Este conjunto de procesos tiene su reflejo en la escena urbana, donde se conforma un paisaje turístico reconocible en muchos sectores de los centros urbanos europeos. Calles y plazas aparecen abarrotadas de visitantes, que deambulan sin prisas a pie o en diferentes medios de movilidad blanda (bicicletas, patinetes, etc.). Su presencia se hace más visible si se desplazan en grupo, autobuses o trenecitos turísticos. Y cuando toman fotografías, ocupan terrazas o hacen cola para acceder a los principales iconos turísticos de la ciudad. En estos sectores proliferan los establecimientos a pie de calle orientados a la demanda turística, desde tiendas de souvenirs hasta locales de ocio nocturno. Y, en función de la trama edificada, establecimientos de alojamiento de diferente tipo: hoteles que ocupan inmuebles completos, hostales y "hostels" en una o varias plantas de un edificio, y VUT donde los turistas ponen a secar su ropa en los balcones. La superficie de tránsito se puebla de expositores y las fachadas de carteles que identifican el negocio. La escena se completa con las instalaciones turísticas vinculadas a los programas de acogida del destino: oficinas de información turística en equipamientos reversibles (quioscos[) y móviles (furgonetas[), señalética turística, etc.

\section{Los efectos de la turistificación: hacia un catálogo de amenazas}

Los centros urbanos están sometidos a un proceso de cambio permanente. En el momento actual, la turistificación es uno de los vectores más importantes de transformación, con efectos sobre las dimensiones formales, funcionales, sociales y simbólicas de estos espacios (García et al., 2017). La inserción de la función turística tiene efectos positivos y negativos. Este apartado se centra en los segundos, ya que son amenazas directas derivadas de la ola actual de turistificación. La conversión de una amenaza en vector real de deterioro va a depender de la intensidad del crecimiento turístico, de las características concretas de los lugares afectados y de las medidas de gobierno adoptadas. La interrelación entre procesos incrementa el riesgo global, ya que las amenazas tienden a retroalimentarse en un círculo vicioso cuyas consecuencias finales son difíciles de discernir. 


\subsection{Deterioro del paisaje urbano}

El turismo de ciudad no genera un paisaje propio, más bien refuncionaliza y resignifica algunos de los paisajes preexistentes, en especial aquellos dotados de valor patrimonial. No obstante, existe una impronta física del turismo vinculado a la implantación de: 1. Palacios de congresos y equivalentes; 2. Hoteles y otros tipos de alojamiento; 3. Instalaciones vinculadas a programas de acogida del destino, como los quioscos de información turística y la señalética; y 4. Cartelería y expositores asociados a los establecimientos turísticos. Además de estas implantaciones directas, hay toda una serie de intervenciones urbanas en las que la motivación turística está presente, desde la creación de grandes contenedores culturales hasta las operaciones de peatonalización. El turismo aparece a nivel de discurso justificativo, aunque su sentido global supera la mera dimensión turística.

Cuando la actividad turística se gestiona de manera deficiente, se produce un deterioro de la forma urbana a distintas escalas (Brandis \& Río, 1995). A nivel del plano, algunas de las grandes implantaciones antes reseñadas son susceptibles de compactar la trama, densificando espacios previamente más porosos. Estas implantaciones también pueden afectar negativamente a las vistas, lo que Zoido (2012) denomina el "paisaje urbano exterior". Sigue siendo frecuente la implantación de grandes equipamientos y hoteles de volumetría excesiva. A pesar de las protestas de algunos colectivos, se han llevado a cabo proyectos como el Hotel Vela de Barcelona y las Setas de Sevilla. La polémica también afecta a la Torre del Puerto de Málaga, diseñada para albergar un hotel de lujo. En muchas ocasiones, estos proyectos cuentan con el apoyo decidido de los gobiernos locales, deseosos de contar con nuevos iconos que renueven la imagen de la ciudad. La inserción de las arquitecturas contemporáneas en los centros históricos y sus entornos visuales siempre ha sido un ámbito abonado a la polémica, por su capacidad de impacto en el paisaje. De hecho está en la génesis del Memorándum de Viena (2005) y toda la doctrina posterior sobre paisaje histórico urbano.

El impacto también puede afectar a la escena urbana, lo que se muestra a cualquier persona en su recorrido por la ciudad. De acuerdo con Fariña (2006), esta escena se compone de elementos estructurantes y otros más epidérmicos. Los primeros dan forma al espacio público: el tejido, los edificios, las alineaciones, los espacios, las alturas. En este caso los efectos negativos derivan de las implantaciones turísticas desajustadas, en una problemática similar a la expresada anteriormente. Los componentes epidérmicos incluyen mobiliario, luces, árboles, terrazas, toldos, antenas, publicidad, pavimentos o fuentes. A partir del análisis de las normativas locales, Fernández \& Santos (2018) han identificado los principales conflictos que genera el turismo sobre esta dimensión del paisaje urbano. De una parte, se genera impacto negativo a nivel del espacio público por la presencia de terrazas, 
instalaciones publicitarias, cierto mobiliario urbano e incluso la presencia de vehículos y visitantes. De otra, se afecta negativamente a las edificaciones debido a una inadecuada implantación de rótulos publicitarios y otros elementos añadidos. Incluso la adaptación al uso turístico de muchos inmuebles puede suponer alterar la estructura de vanos de la fachada, modificando las características tipológicas de los edificios afectados.

El resultado final es una imagen urbana deteriorada, con fuerte presencia de elementos turísticos que generan contaminación visual. Se conforman así paisajes turísticos a nivel de escena urbana fácilmente reconocibles en todas partes del mundo. Son, en cierto sentido, paisajes de la globalización, pero en su dimensión más banal y estética más deteriorada.

\subsection{Incremento de la congestión y la contaminación}

Como se ha señalado anteriormente, la turistificación implica la presencia de un mayor número de visitantes en determinados sectores del espacio urbano. De forma paralela, aumenta el número de vehículos en circulación, ya sean vehículos genéricos utilizados por los visitantes para acceder y/o moverse por el destino o correspondan a productos turísticos basados en la movilidad. Además del incremento cuantitativo, hay que tener en cuenta que turistas y excursionistas entorpecen el desplazamiento de otros usuarios del espacio urbano, ya que su movimiento es más lento y errático. De una parte, desconocen los lugares por donde se mueven, por lo que su orientación es más difícil. De otra, en muchas ocasiones se aproximan a estos lugares en una lógica de contemplación, lo que implica un ritmo de movimiento más pausado.

Los visitantes y sus vehículos intensifican la congestión de algunos espacios ya previamente saturados. La congestión se produce en las calles y plazas donde se concentran turistas y excursionistas. Afecta a los estacionamientos, los servicios de transporte público, las zonas verdes, las playas y determinadas tiendas y establecimientos de hostelería. Y también a museos y otros espacios culturales, cuyas colas sobre las calles adyacentes derivan en problemas de gestión urbana. Desde aproximaciones econométricas, los efectos de la congestión se han analizado en lugares como Amberes (Neuts, 2016) y Amsterdam (Neuts et al., 2012). De forma más general, implica una competencia por recursos escasos entre distintos tipos de usuarios. Dentro de éstos, la población local tiende a evitar los espacios y momentos que considera más congestionados por motivo del turismo. El problema radica en que se está ampliando esta congestión tanto en el espacio como en el tiempo. En consecuencia, aumenta la presión de ciertos grupos de interés para solventar estas situaciones aumentando la capacidad de infraestructuras y servicios (aeropuertos, aparcamientos, etc.), lo que a su vez puede acelerar el proceso de turistificación. 
La mayor presencia de visitantes también presiona sobre los sistemas de abastecimiento de aguas, saneamiento y recogida de residuos sólidos. Sobre todo supone incrementar la contaminación acústica y atmosférica. La primera está especialmente asociada al ocio nocturno, pero también a la ocupación de terrazas y veladores. La segunda se incrementa por prácticas como el encendido continuo de los motores de los autobuses discrecionales para refrigerar su interior. La turistificación implica incremento de la congestión y de la contaminación, sobre todo en ausencia de acciones de política pública expresa. No obstante, resulta difícil ponderar el peso del turismo en problemas de este tipo. En cambio su contribución sí está clara cuando se trata de los cruceros. Además de los residuos que dejan en alta mar, suponen un vector importante de contaminación atmosférica de las ciudades donde atracan (García, 2017). Entre otras razones, porque recurren a un fuel más barato y tóxico que el de uso habitual en el transporte terrestre. De otra parte, depositan en tierra de forma abrupta miles de pasajeros que se mueven en grupo por la ciudad o toman distintos vehículos para realizar excursiones. Las embarcaciones son cada vez mayores y los puertos se adaptan para permitir su atraque. Como resultado, se incrementan los niveles de congestión urbana. Debido a la especial idiosincrasia, este conjunto de problemas adquiere una especial relevancia en Venecia (Testa, 2011; Seraphina et al., 2018), ciudad especialmente vigilada por UNESCO debido a su condición de Patrimonio de la Humanidad (Trancoso-González, 2018).

\subsection{Simplificación funcional}

En líneas generales, el centro histórico corresponde a la ciudad preindustrial. Lo que hoy es una pieza de la aglomeración urbana, antes fue la ciudad total: un ámbito que concentraba todas las funciones en un espacio relativamente reducido. Esta concentración de funciones dota de singularidad a estos centros como piezas urbanas y es uno de sus valores patrimoniales. Es más, la conversión de muchos de estos espacios en los centros urbanos de sus ciudades ha potenciado el desarrollo de funciones asociadas a la centralidad, con una influencia sobre el territorio que supera los límites municipales. En estos sectores más dinámicos siempre ha existido una fuerte presión de terciarización.

Como se ha señalado en epígrafes anteriores, la oleada actual de turistificación supone: 1. Un crecimiento del alojamiento turístico convencional y establecimientos como tiendas de recuerdos; 2. Una reorientación hacia los visitantes de comercio y hostelería; y 3. La progresiva conversión de la vivienda en mercancía turística. En las áreas sometidas a estos procesos se asiste a un declive de la función residencial, aspecto que se tratará más adelante, y un empobrecimiento del entramado de actividades productivas, que puede llegar a suponer la aparición de espacios de monocultivo turístico. 
El diferencial de rentas entre usos turísticos y no turísticos explica el desplazamiento de ciertos tipos de comercios de proximidad y actividades manufactureras, en muchos casos de raigambre artesana. Además las situaciones de congestión y una imagen urbana asociada al turismo pueden incidir negativamente sobre el terciario de oficinas y negocios similares.

Además de los grandes edificios ocupados por hoteles y apartamentos turísticos, el cambio más notable se produce en los locales a pie de calle. La turistificación supone una simplificación del tejido comercial y hostelero. Esta simplificación no implica tanto una reducción de la oferta como en su reorientación hacia un consumidor foráneo en detrimento de la clientela local. Cierran o se transforman los establecimientos de proximidad, lo que dificulta el abastecimiento de los vecinos de estos barrios. Cierran también comercios centenarios, que forman parte de la memoria de la ciudad. Y en cambio se extienden las tiendas de recuerdos, el comercio de las grandes marcas y los establecimientos vinculados al entretenimiento, en especial determinadas fórmulas de hostelería. En todo caso no se trata de un proceso nuevo, sino de un fenómeno que se ha intensificado durante los últimos años y se expande a nuevas áreas de la ciudad.

El sentido y la intensidad de la transformación están determinados por factores como la estructura comercial y hostelera preexistente y el volumen de la demanda asociada al turismo. A veces supone una sofisticación de la oferta, que implica una "gourmetización" de restaurantes y tiendas de alimentación. En otras ocasiones simplemente se refuerza el paisaje turístico típico, con calles repletas de tiendas de recuerdos que presentan sus productos en expositores externos; bares, cafeterías y restaurantes de cocina adaptada a los gustos y precios foráneos; y tiendas de moda y complementos de marcas reconocibles a nivel internacional. En general, la sofisticación brilla por su ausencia. Es más, la progresiva especialización turística en productos y precios puede llegar a disuadir de acudir a estos espacios al resto de la población de la ciudad, lo que a su vez refuerza dicha especialización.

\subsection{Declive residencial}

En su versión actual, la turistificación incide muy negativamente sobre la función residencial. El diferencial de renta entre alojamiento comercial y vivienda es el vector que amenaza la condición de estos centros como espacios habitados, uno de los objetivos centrales de las políticas urbanas desde hace al menos 30 años. Edificios de propiedad horizontal con usos residenciales se transforman en hoteles-boutique o apartamentos. Esta transformación implica procesos administrativos bastante prolongados y ajustados al marco urbanístico vigente. En cambio, la conversión de una vivienda en una vivienda turística es un proceso mucho más rápido, que se aprovecha además de la falta de regulación 
a diferentes niveles. Las expectativas de los usos vinculados al alojamiento comercial elevan los precios de los bienes inmuebles y, en definitiva, dificultan el acceso a la vivienda en propiedad.

Esta situación es aún más palpable en el mercado del alquiler. Los estudios realizados en Barcelona (Arias, 2018) indican que el alquiler turístico de corta duración puede llegar a ser hasta cuatro veces más rentable que el alquiler de larga duración, sobre todo en aquellos barrios donde el alquiler es más bajo. En este sentido, Blanco \& Blázquez (2019) apuntan a una relación directa entre "mercantilización turística de la vivienda" y "burbuja del alquiler". No obstante, más allá de las afirmaciones generales resulta difícil determinar el peso de dicha mercantilización en el incremento constatado de los precios del alquiler, ya que confluye con diferentes factores: un crecimiento de la demanda que deriva tanto de la recuperación económica como de las dificultades de acceso a la compra de vivienda; las modificaciones del marco regulatorio tendentes a una liberalización del mercado del alquiler; y la acción de SOCIMls y otros inversores que han entrado con fuerza en el sector. De hecho, los únicos trabajos que han intentado cuantificar el impacto de las VUT sobre el mercado del alquiler derivan de encargos de las patronales del sector, lo que plantea dudas sobre credibilidad. Para Madrid, FEVITUR (2018) señala que este impacto se limita al distrito Centro, en una cuantía del 1,19\% sobre el total del incremento del precio del alquiler. Es más, se limita dicho impacto a cuatro barrios del distrito: Palacio, Sol y, especialmente, Lavapiés-Embajadores y Chueca-Justicia.

Las dificultades para acceder a la vivienda son el principal factor que favorece el declive residencial. Pero también influye la turistificación de la oferta comercial y hostelera, ya que productos y precios están más orientados a los consumidores foráneos que a los vecinos. El declive también está favorecido por las molestias que generan los visitantes, desde la congestión hasta los problemas de convivencia a los que se aludirá en el apartado siguiente.

Desde la corriente crítica, se ha prestado especial atención al proceso de cambio social que afecta a los barrios afectados por la turistificación. En origen, se consideraba una manifestación adicional de la gentrificación, de sustitución de población de bajos ingresos por otros grupos de clase media y mediaalta. Con el paso del tiempo, se ha empezado a considerar una forma singular de gentrificación (Cócola, 2018), que implica la sustitución de población residente por visitantes, e incluso como dos procesos diferentes (Sequera \& Nofre, 2018), que pueden coexistir en los mismos espacios en una situación de equilibrio inestable.

Más allá de las interpretaciones generales, los datos disponibles no permiten obtener conclusiones irrebatibles. Registrar la dinámica sociodemográfica de los centros resulta difícil debido a la fuerte movilidad de la población. Además confluyen procesos muy distintos en periodos de tiempo bastante 
cortos. Estas dificultades quedan patentes en el trabajo de López-Gay \& Cócola (2016) sobre el barrio Gótico de Barcelona, quizás el intento más consistente de apoyar las teorías en datos, para lo que se recurre al instrumental de análisis demográfico. Como señalan estos autores, este barrio tiene la mayor presión turística de Barcelona, con una capacidad de alojamiento que iguala a la población residente. En cifras aproximadas, pasó de 30000 habitantes en 1970 a 15000 en 1996. Después de este fuerte retroceso, la población del barrio ascendió a casi 18000 personas entre 2008 y 2010, fruto tanto de una inmigración extranjera de bajos recursos como a un proceso incipiente de gentrificación. La aportación más interesante del trabajo estriba en que compara las dinámicas del barrio Gótico y otros barrios también gentrificados de Barcelona pero con menor presión turística. Y los resultados apuntan a una mayor pérdida de población y hogares en el Gótico, así como mayores cambios en la estructura sociodemográfica por incorporación de extranjeros de elevado nivel de instrucción (fundamentalmente Europa y Norteamérica) y salida de población nacional en grupos de edad avanzada y/o con niños pequeños. En suma, se estaría produciendo un declive de la función residencial, de sustitución de familias con hijos por una población flotante poco vinculada al lugar, una sustitución que afectaría incluso a los primeros gentrificadores del barrio. Aunque no se han realizado trabajos tan detallados, es posible que esta situación se repita en otros barrios de grandes ciudades en proceso acusado de turistificación. En todo caso falta por elaborar trabajos equivalentes en centros de ciudades menos dinámicas, donde la presión turística está creciendo pero que no registraron procesos anteriores de inmigración / gentrificación.

\subsection{Rechazo local al turismo}

El estudio de la percepción de la comunidad local sobre el turismo tiene amplia tradición. Existen trabajos notables de principios de siglo (Haley et al., 2005), cuyos planteamientos, técnicas y resultados han sido sometidos a contraste en contextos urbanos muy diferentes (Chen \& Chen, 2011; Lee et al., 2007). En general, la actitud de la población residente ante el desarrollo turístico se considera una de las dimensiones críticas de la capacidad de carga social de un territorio. Dicha actitud, que nunca va a ser homogénea, viene determinada por una multiplicidad de aspectos (Almeida et al., 2015). Entre otros, es frecuente citar el nivel de dependencia económica con el turismo, el sentido de apego al lugar y el grado de contacto directo con turistas y excursionistas. Es mayoritario el recurso a encuestas, en las que se pide al entrevistado que se posicione en relación a determinadas cuestiones. En líneas generales, los trabajos más institucionales sobre "overtourism" replican estas características (Postma \& Schmuecker, 2017). 
La reciente ola de turistificación ha supuesto un incremento local del rechazo al turismo, en especial en aquellos barrios donde la presencia de visitantes era hasta hace poco tiempo testimonial. A nivel personal, surgen problemas de convivencia. Los turistas acceden a sus alojamientos en horarios poco compatibles con el descanso de la población residente, ya que es frecuente que aprovechen los vuelos más baratos. El ruido de los "trolleys" retumba en las calles y el trasiego de visitantes en los portales de los edificios con viviendas de uso turístico es continúo. Si además los visitantes tienen comportamientos incívicos (fiestas en la madrugada, consumo desmesurado de alcohol, etc.), los problemas de convivencia se acrecientan. Como resultado, el atractivo de estos lugares como espacios residenciales disminuye, en especial para las familias con menores a su cargo.

De las dificultades de convivencia deriva un sentimiento general de extrañamiento, de desapego progresivo a un lugar que cada vez se reconoce como menos propio. Este desapego afecta a la comunidad local, pero también se puede extender al resto de la población de la ciudad. El centro puede llegar a ser percibido como un espacio preferentemente turístico. Con ello pierde carga simbólica; se acentúa el proceso de vaciado de significados que está en la base de la desposesión simbólica de esta parte de la ciudad (Benach, 2016). El extrañamiento se hace más doloroso cuando la comunidad percibe que los gobiernos locales atienden más al turismo que al bienestar de la ciudadanía. Y no tanto al turismo en sí mismo como a algunos sectores del negocio turístico, en una confluencia de intereses en la que los vecinos reciben los inconvenientes del crecimiento turístico pero no sus beneficios potenciales.

Medir los sentimientos de extrañamiento y desposesión simbólica no resulta fácil, sobre todo considerando la pluralidad intrínseca a las sociedades contemporáneas. En cambio, resulta mucho más fácil identificar las muestras más o menos organizadas de oposición al turismo impulsadas por ciertos movimientos sociales: ataques a instalaciones turísticas, pintadas en paredes, concentraciones ciudadanas de protesta, activismo en redes sociales, etc. Manifestaciones de este tipo pueden encontrarse en muchas ciudades del mundo (véase al respecto la compilación de Colomb \& Novy, 2016) y son la base de la actividad de plataformas como la Assemblea de Barris per un Turisme Sostenible (Barcelona), Málaga no se Vende (Málaga), Lavapiés dónde Vas (Madrid) o Ciutat per a qui I'habita, no per a qui la visita (Palma). En general se trata de acciones muy minoritarias, aunque magnificadas a nivel mediático y base de un número creciente de trabajos académicos de corte crítico (Cabrerizo, 2016; Gil \& Sequera, 2018). Englobadas bajo el término de "turismofobia" (Alcalde et al., 2018; Milano, 2018), se presentan como un movimiento de defensa del derecho a una ciudad en el sentido lefebreviano, una ciudad libre de presiones mercantilistas y burocráticas (Blanco et 
al., 2018). Si bien su alcance y sentido son objeto de notable controversia (Huete \& Mantecón, 2018), no cabe duda de que se trata de un nuevo frente de conflicto urbano (Romero, 2018).

\subsection{Deterioro del atractivo turístico}

La turistificación puede ocasionar también un deterioro de atractivo turístico y, en esencia, una pérdida de competitividad de la ciudad como destino de visita. Se trata de un aspecto de especial interés para las administraciones locales del turismo, que aparece expresamente recogido en los documentos institucionales sobre "overtourism" (por ejemplo: WTO, 2018). De hecho, se ha considerado una dimensión adicional de la capacidad de carga social de un destino, que sería sobrepasada en situaciones de deterioro significativo de la satisfacción del visitante.

En principio, la masificación y congestión asociada deterioran la experiencia turística. Entre otros inconvenientes, implica largas esperas para acceder a museos y monumentos, dificultades para conseguir sitio en bares y restaurantes, sospecha de un incremento abusivo de los precios de bienes y servicios, abarrotamiento en calles y plazas $\square$ e incluso la sensación de pérdida de autenticidad de los lugares visitados, aspecto especialmente sensible en los lugares del patrimonio urbano. Ya existe un buen número de trabajos que abordan la congestión turística desde la perspectiva de los visitantes (Riganti \& Nijkamp, 2008; Neuts \& Nijkamp, 2012; jin et al., 2016). La percepción sobre la sensación de aglomeración está influida por los rasgos personales del turista (motivaciones, expectativas, etc.), una serie de variables ambientales (por ejemplo, la calidad atribuida al entorno) y las características de los otros visitantes (comportamiento, etc.). En líneas generales se trata de trabajos basados en encuestas que recurren a planteamientos de la psicología ambiental.

En buena medida, los resultados obtenidos no sostienen una relación directa entre masificación y pérdida de competitividad turística. Los visitantes sí reconocen situaciones de saturación e incluso pueden ser percibidas en términos negativos. Sin embargo, tienden a asumir estos momentos como algo intrínseco a determinados destinos. Los trabajos realizados en Florencia por Popp (2012) reflejan la complejidad del tema. A partir de una metodología cualitativa, capta los momentos y lugares donde los turistas perciben hacinamiento. En estas ocasiones la congestión por una densidad turística excesiva sí deteriora la experiencia del lugar. Pero también identifica situaciones de aglomeración positiva: los visitantes entienden que cierto barullo forma parte de una ciudad viva y la propia presencia de otros turistas genera sensación de seguridad al viajero menos experimentado.

La congestión es un rasgo característico de las ciudades de mayor trayectoria turística. En cambio, el rechazo explícito al turismo que muestran algunos colectivos es un fenómeno mucho más reciente, cuyo impacto sobre el atractivo de los destinos está todavía por determinar. El turismo se basa en la 
hospitalidad, aunque se trate de una hospitalidad mercantilizada. Es una cuestión que preocupa sobremanera a las autoridades públicas del turismo y a los representantes de la industria turística de las ciudades donde los conflictos aparecen con más virulencia. Frente a estos destinos, en otros se enfatiza la buena acogida al visitante como nuevo argumento promocional.

Como se ha señalado, la mayoría de los trabajos se basan en estudios sobre los visitantes en destino. Falta por determinar cómo afecta la percepción sobre la congestión y hostilidad en el proceso de selección del destino, sobre todo en relación a las noticias que aparecen en los medios de comunicación de masas. Y, si en destino se ha sentido hacinamiento y/o rechazo, cómo afectan estas experiencias a las recomendaciones de viaje. Además hay que tener en cuenta la pluralidad de los visitantes, en relación a motivaciones, expectativas, niveles de gasto, etc. Aunque no se perciban efectos negativos a nivel general, algunos tipos de turistas pueden ser mucho más sensibles a estas situaciones, lo que puede provocar una sustitución de unos segmentos de la demanda por otros. En el peor de los casos, esta sustitución puede suponer un deterioro de la imagen del destino e incluso profundizar en los procesos de turistificación.

\section{A modo de reflexiones finales}

Como señalábamos en la presentación, abordamos la elaboración del artículo con ánimo de clarificar un debate bastante enmarañado. Nuestra reflexión parte del conjunto de estudios del turismo en la ciudad, un bagaje de conocimiento colectivo elaborado por miembros de una comunidad científica multidisciplinar con bastantes conexiones con el aparato institucional del turismo, también a nivel del gobierno urbano.

Dentro de estos estudios, los temas relativos al impacto del turismo conforman un ámbito de trabajo consolidado. Sin embargo, su avance siempre se ha encontrado con una serie de limitaciones. En primer lugar, la dificultad para delimitar el turismo a nivel urbano. En una ciudad, visitantes y residentes comparten bastantes espacios, tiempos y actividades. Excepto algunos usos estrictamente vinculados a la función turística, la impronta espacial del turismo es limitada, aunque los visitantes forman parte ineludible de la escena urbana contemporánea. En una época de hipermovilidad, la propia distinción entre visitante y residente está en cuestión. Y esta afirmación es especialmente válida para los centros urbanos, espacios utilizados por una multiplicidad de colectivos. Es más, las fronteras entre unos y otros son bastante líquidas, y aparecen nuevas figuras "intersticiales" en las formas de vivir la ciudad (Quaglieri \& Russo, 2010). No cabe duda de que aumenta la presión sobre los espacios centrales, especialmente de las ciudades más dinámicas, aunque cabe plantearse si esta presión se debe al turismo o responde a procesos más generales con implicaciones a nivel de dinámica urbana. 
Otra limitación deriva de la necesidad de adoptar juicios de valor para determinar si un proceso es positivo o negativo. La turistificación es ineludible al desarrollo del turismo en la ciudad. Y se intensifica por el simple crecimiento de la afluencia de visitantes. ¿En qué punto muchos visitantes son demasiados? ¿Cuándo la popularidad turística deja de ser reflejo de éxito para convertirse en exponente de un problema? En buena medida, esta limitación deriva de la dificultad para aprehender lo urbano en todas sus dimensiones. La presión turística viene determinada tanto por variables relacionadas con la afluencia de visitantes como por las características del lugar. En general los estudios del turismo en la ciudad se han centrado sobre el primer conjunto de variables, minimizando la importancia de la singularidad de cada centro. Esta singularidad deriva de la propia conformación física, del entramado de relaciones sociales y funcionales, de la dinámica global de la ciudad donde se sitúa, del programa y la capacidad locales de gobierno urbanol y también de la propia trayectoria turística. La condición de algunos centros como bienes patrimoniales puede ayudar a proporcionar una línea de base para valorar procesos en curso, aunque no resulta fácil determinar si estos procesos colaboran en la salvaguarda o deterioro de estos espacios.

Los enfoques recientes sobre la relación turismo y ciudad ayudan sólo parcialmente a resolver estas limitaciones. Los trabajos sobre "overtourism", que enlazan bastante con los estudios sobre capacidad de carga, implican un desarrollo de sistemas de indicadores de carga turística, a escala de conjunto urbano o para determinados sectores de la ciudad. La ausencia de datos convencionales puede empezar a suplirse recurriendo a los "big data", aunque se corre el riesgo de elaborar meros ejercicios cuantitativos de contenido insustancial. De otra parte, los indicadores al uso permiten comparar niveles de presión turística entre destinos, pero no reflejan necesariamente el riesgo o la existencia de situaciones de sobrecarga. Ello seguirá haciendo ineludible recurrir a las valoraciones de "stakeholders", cuyas posiciones vienen determinadas por sus intereses directos, y a la percepción de los implicados, desde los vecinos hasta los turistas. $Y$ no es cuestión fácil si se atiende a la consideración de estos espacios como lugares centrales y bienes patrimoniales, lo que implica responsabilidades compartidas en órdenes que superan lo estrictamente local.

El conjunto de trabajos de la corriente crítica supone un revulsivo para la línea tradicional de los estudios del turismo en la ciudad. Este impulso no deriva necesariamente de sus planteamientos generales, demasiado ensimismados en una crítica frontal al orden económico e institucional vigente. En una visión ahistórica, se suele presentar los centros como arcadias felices sujetas a un proceso reciente de mercantilización cuya quintaesencia es el turismo. Desde nuestra perspectiva, resulta mucho más relevante alguna de sus aportaciones de rango intermedio: el énfasis en el componente social, el derecho a la vivienda y el derecho a la ciudad, aspectos que tienden a minimizarse en 
muchos trabajos de base patrimonial; las posibilidades que tiene el recurso al concepto de desplazamiento como criterio para determinar el carácter positivo o negativo de la dinámica turística; la aplicación del diferencial de rentas para explicar el proceso general de sustitución de usos y, de forma específica, la intensificación de las usos vinculados al turismo; o la orientación activista con implicación directa en los movimientos sociales, un contrapunto interesante a una línea convencional que oscila entre el aislamiento propio de la academia y una vinculación demasiado estrecha con la institucionalidad del turismo. El concepto de gentrificación turística, de indudable éxito en términos de marketing mediático y académico, puede acabar convirtiéndose en un lastre que limite las posibilidades de aproximación al estudio del turismo y sus efectos en la ciudad.

Desde que los turistas llegan a la ciudad existen procesos de turistificación e incluso de contestación social al turismo, como se refleja en trabajos de cariz histórico (Fernández, 2018). Estos procesos se insertan en el marco general de la terciarización. Desde el resurgimiento del turismo de ciudad en la década de 1990, ha habido periodos de crecimiento y otros de cierta recesión, que además han afectado de forma desigual a distintas ciudades. El momento actual es de fuerte crecimiento, lo que implica una intensificación de los procesos previos de turistificación. Sin embargo y tomando como referencia las ciudades españolas, este crecimiento se puede frenar e interrumpir, no tanto por los cambios en las causas subyacentes (abaratamiento del viaje, incremento del atractivo urbano, etc.) como por una reorientación de los flujos turísticos hacia otros destinos competidores.

Si bien la turistificación es un fenómeno de larga trayectoria, la ola actual presenta como singularidad la transformación de la vivienda en mercancía turística. La acción de las empresas de plataformas digitales ha permitido la aparición de una nueva oferta de alojamiento que supone una disrupción en este campo de juego. Ante este cambio, el sector hotelero se moviliza para defender su posición dominante en el negocio turístico local. Si no consiguen frenar la proliferación de viviendas de uso turístico, acabarán explorando las posibilidades de negocio de esta nueva fórmula de alojamiento. Los gobiernos pierden capacidad para controlar la implantación de las actividades turísticas, dada la liquidez de esta oferta y el poder de un número limitado de empresas de plataforma que operan a nivel global. No obstante, el mayor problema deriva de la presión añadida sobre la condición residencial de los centros, ya que reduce el parque de viviendas disponible para la población residente en la ciudad. El riesgo que suponía la turistificación para mantener esta condición residencial (ruido, transformación comercial, masificación del espacio públicol) ha devenido en amenaza directa, que afecta piso a piso, bloque a bloque, barrio a barrio. 
La reciente expansión de la huella turística, protagonizada en parte por un visitante que busca diferenciarse del turista más convencional, muestra la complejidad y dinamismo del turismo urbano. Esta expansión conlleva turistificación y, de forma novedosa, respuesta activa de los movimientos sociales. Los problemas no son nuevos (museificación, tematización, ludificación]), si acaso los términos que los identifican (gentrificación, airbanización, "overtourism"ם) que implican una nueva mirada sobre procesos cada vez más críticos para la salvaguarda urbana y patrimonial de nuestros centros urbanos.

Agradecimientos: Este artículo se ha elaborado en el marco del Proyecto de investigación "Transformaciones del paisaje urbano histórico inducidas por el turismo: contradicciones y controversias, gobierno y gobernanza local (PAITUR-Ciudad)". Proyecto CSO2016-75470-R del Programa Estatal de I+D+i del Ministerio de Economía, Industria y Competitividad (2016-2020).

Declaración responsable: El autor declara que no existe ningún conflicto de interés en relación con la publicación de este artículo. 


\section{Bibliografía}

Alcalde Garcia, J., Guitart Casalderrey, N., Pitarch Mach, A., \& Vallvé Fernández, O. (2018). De la turismofobia a la convivencia turística: el caso de Barcelona. Análisis comparativo con Ámsterdam y Berlín. ARA, 8(2), 25-34. Retrieved from http://revistes.ub.edu/index.php/ara/article/view/21980 Almeida García, F. (2007). Análisis de la estructura turística de las ciudades Patrimonio de la Humanidad de España. Baética, 29, 57-72. http://dx.doi.org/10.24310/BAETICA.2007.v0i29.225 Almeida García, F.; Balbuena Vázquez, A. \& Cortés Macías, R. (2015). Resident's attitudes towards the impacts of tourism. Tourism Management Perspectives, 13, 3340. https://doi.org/10.1016/j.tmp.2014.11.002

Arias Sans, A. (2018). Turismo y gentrificación. Apuntes desde Barcelona. Papers. Regió Metropolitana de Barcelona. Territori, estratègies, planejament, 60, 130-139. Retrieved from https://www.raco.cat/index.php/PapersIERMB/article/view/339245

Ashworth, G. \& Page, S.J. (2011). Urban tourism research: Recent progress and current paradoxes. Tourism Management, 32, 1-15. https://doi.org/(...).tourman.2010.02.002

Ashworth, G.J. \& Tunbridge, J.E. (1990). The Tourist-Historic City. London: Belhaven Press.

Austrian Hotelier Association (2018). Protecting your city from overtourism. European city tourism study 2018. Munich: Roland Berger GmbH.

Barrado Timón, D. (2010). Gran ciudad y turismo en la transición postindustrial: nuevos y viejos procesos, nuevas y viejas teorías. El ejemplo del área metropolitana de Madrid. Scripta Nova, XIV(317). Retrieved from http://www.ub.edu/geocrit/sn/sn-317.htm

Benach Rovira, N. (2016). ¿Ciudades en el mapa o en la guía turística? Venta de la ciudad y sentido del lugar. Revista CIDOB d'Afers Internacionals, 13, 89116. https://doi.org/10.24241/rcai.2016.113.2

Blanco Romero, A., \& Blázquez Salom, M. (2019). Marchandisation touristique du logement et planification urbaine a Barcelone. Sud-Ouest Européen, 46, 9-22.

Blanco Romero, A., \& Blázquez Salom, M. \& Morell M. (2018). Turismofobia como arma arrojadiza. Ábaco. Revista de Cultura y Ciencias Sociales, 4 (98), 55-64.

Brandis, D., \& Río, I. del (1995). Turismo y medio ambiente en las ciudades históricas. Anales de Geografía de la Universidad Complutense, 15, 151-161. Retrieved from https://revistas.ucm.es/index.php/AGUC/article/view/AGUC9595220157A 
Bures, R.M., \& Cain, C. (2008). Dimensions of gentrification in a tourist city. Paper proposal submitted for presentation at the 2008 Meeting of the Population Association of America. Department of Sociology, University of Florida.

Cabrerizo, C. (2016). La ciudad negocio. Turismo y movilización social en pugna. Madrid: Cisma Editorial.

Calle Vaquero, M. de la (2002). La ciudad histórica como destino turístico. Barcelona: Ariel.

Calle Vaquero, M. de la, Ferreiro Calzada, E., \& Mendoza de Miguel, S. (2018). Concentración y desconcentración de la actividad turística sobre el espacio urbano. Reflexiones en torno a Madrid. Polígonos, 30, 143-170. http://dx.doi.org/10.18002/pol

Campesino Fernández, A.J. (Dir.) (1999). Comercio, turismo y cambios funcionales en las Ciudades Españolas Patrimonio de la Humanidad. Cáceres: Cámara Oficial de Comercio e Industria de Cáceres.

Cazes, G., \& Potier, F. (1996). Le tourisme urbain. Paris: Presses Universitaries de France.

Chen, C.-F., \& Chen, P.-C. (2011). Resident attitudes toward heritage tourism development. Tourism Geographies, 12 (4), 525-545. https://doi.org/10.1080/14616688.2010.516398

Colomb, C., \& Novy, J. (Ed.) (2016). Protest and resistance in the tourist city. Abingdon, Oxon - New York, NY: Routledge.

Cócola Gant, A. (2011). El Barrio Gótico de Barcelona. De símbolo nacional a parque temático. Scripta Nova, 15. https://doi.org/10.1344/sn2011.15.3393

Cócola Gant, A. (2018). Tourism gentrification. In L. Lees \& M. Phillips, M. (Eds.), Handbook of Gentrification Studies (pp. 281-293). Cheltenham and Northampton: Edward Elgar Publishing.

Cordente Rodríguez, M., Esteban Talaya, A., Mondéjar Jiménez, J.A., \& Andrés Martínez, M.E. (2012). Medición de motivaciones de turismo cultural en Ciudades Patrimonio de la Humanidad. Revista de Análisis Turístico, 11, 80-85. https://doi.org/10.1234/RAT2011n11

Crespi Vallbona, M., \& Domínguez Pérez, M. (2016). Los mercados de abastos y las ciudades turísticas. Pasos, 14(2), 401-416. Retrieved from hnt://www.pasosonline.org/es/articulos/910crespi

Donaire Benito, J.A., \& Galí Espelt, N. (2008). Modeling tourist itineraries in heritage cities. Routes around the Old District of Girona. Pasos, 6(3), 435449. https://doi.org/10.25145/j.pasos.2008.06.033 
Donaire Benito, J.A., \& Galí Espelt, N. (2011). La imagen turística de Barcelona en la comunidad de flickr. Cuadernos de Turismo, 27, 291-303. Retrieved from https://revistas.um.es/turismo/article/view/139961

Evans, G. (2002). Living in a World Heritage City: stakeholders in the dialectic of the universal and particular. International Journal of Heritage Studies, 8(2), 117-135.

https://doi.org/10.1080/13527250220143913

European Cities Marketing (2018). Managing Tourism Growth in Europe. The ECM Toolbox.

Fariña Tojo, J. (2006). Formas de regulación de la escena urbana en varias ciudades europeas. Cuadernos de Investigación Urbanística, 48, 1-93. Retrieved from http://polired.upm.es/index.php/ciur/article/view/263

Fernández Tabales, A. (2018). Turismofobia "avant la lettre" en la Sevilla de 1929: El viejo debate entre autenticidad y mercantilización del patrimonio. Otarq Revista, 3, 131-148. Retrieved from http://revistas.jasarqueologia.es/index.php/otarq/article/view/225

Fernández Tabales, A., \& Santos Pavón, E. (2018). La difícil convivencia entre paisaje urbano y turismo: clasificación de conflictos y propuestas de regulación a partir del análisis comparativo de normativas locales. Boletín de la Asociación de Geógrafos Españoles, 78, 180211. hntp://dx.doi.org/10.21138/bage. 2715

FEVITUR - Federación Española de Asociaciones de Viviendas y Apartamentos Turísticos (2018). El impacto de las viviendas de alojamiento turístico en el mercado del alquiler residencial en Madrid. Resumen ejecutivo. FEVITUR.

Freytag, T., \& Bauder, M. (2018). Bottom-up touristification and urban transformations in Paris. Tourism Geographies, 20(3), 443-460, https://doi.org/10.1080/14616688.2018.1454504

Füller, H., \& Michel, B. (2014). Stop Being a Tourist!' New dynamics of urban tourism in BerlinKreuzberg. International Journal of Urban and Regional Research, 38(4), 13041318. https://doi.org/10.1111/1468-2427.12124

Galí Espelt, N., Donaire, J.A., Martínez-Garcia, E., \& Mundet i Cerda, L. (2015). Turistas entre monumentos. El comportamiento de los visitantes en el centro histórico de Girona (2003 y 2013). Revista Iberoamericana de Turismo - RITUR, 5(2), 70-84. https://doi.org/10.2436/20.8070.01.5 García, M. (2017). Cruceros: Colosos del turismo masivo de alta contaminación. Ecología Política, 52, 98-102. Retrieved from https://www.ecologiapolitica.info/novaweb2/?p=6801 
García, L. M.; Smith, N., \& Mejías, M.A. (2007). Gentrification, displacement, and tourism in Santa Cruz de Tenerife. Urban Geography, 28(3), 276-298. https://doi.org/10.2747/02723638.28.3.276

García Henche, B. (2017). Los mercados de abastos y su comercialización como producto de turismo de experiencias. El caso de Madrid. Cuadernos de Turismo, 39, 167189. https://doi.org/10.6018/turismo.39.290491

García Hernández, M. (2000). Turismo y medio ambiente en ciudades históricas. De la capacidad de acogida turística a la gestión del flujo de visitantes. Anales de Geografía de la Universidad Complutense, 20, 131-148. Retrieved from

https://revistas.ucm.es/index.php/AGUC/article/view/AGUC0000110131A

García Hernández, M. (2003). Turismo y conjuntos monumentales: Capacidad de Acogida Turística y Gestión de Flujos de Visitantes. Valencia: Tirant lo Blanch.

García Hernández, M., Calle Vaquero, M. de la, \& Yubero Bernabé, C. (2017). Cultural heritage and urban tourism: historic city centres under pressure. Sustaninability, 9, 1346. https://doi.org/10.3390/su9081346

Gil, J., \& Sequera, J. (2018). Expansión de la ciudad turística y nuevas resistencias. El caso de Airbnb en Madrid. EMPIRIA. Revista de Metodología de Ciencias Sociales, 41, 1532. https://doi.org/10.5944/empiria.41.2018.22602

Glasson, J. (1994). Oxford: a heritage city under pressure. Visitors, impacts and management responses. Tourism Management, 15(2), 137-144. https://doi.org/10.1016/0261-5177(94)90007-8 Glasson, J., Godfrey, K., Goodey, B., Absalom, H., \& van der Borg, J. (1995). Towards Visitor Impact Management: Visitor Impacts, Carrying Capacity and Management Responses in Europe's Historic Towns and Cities. Aldershot: Avebury.

Gotham, K. F. (2005). Tourism gentrification: The case of New Orleans' Vieux Carre (French Quarter). Urban Studies, 42(7), 1099-1121. https://doi.org/10.1080/00420980500120881

Hallyar, B., Griffin, T., \& Edwards, D. (Eds.). (2008). Urban tourism precincts. Oxford: Elsevier.

Gutiérrez, J., García-Palomares, J.C., Romanillos, G., \& Salas-Olmedo, M.H. (2017). The eruption of Airbnb in tourist cities: Comparing spatial patterns of hotels and peer-to-peer accommodation in Barcelona. Tourism Management, 62, 278-291. https://doi.org/10.1016/j.tourman.2017.05.003 
Haley, A. J., Snaith, T., \& Miller, G. (2005). The social impacts of tourism: a case study of Bath, UK. Annals of Tourism Research, 32(3), 647-668. https://doi.org/10.1016/j.annals.2004.10.009

Herrero Prieto, L.C., Sanz Lara, J.A., Bedate Centeno, A., Devesa Martínez, M., \& Barrio Tellado, M.J. del (2004). Turismo cultural e impacto económico de Salamanca 2002. Ciudad Europea de la Cultura. Madrid: Thomson-Civitas.

Hiernaux, D., \& González, C.I. (2014). Turismo y gentrificación: pistas teóricas sobre una articulación. Revista de Geografía Norte Grande, 58, 55-70. Retrieved from https://scielo.conicyt.cl/pdf/rgeong/n58/art04.pdf

Huete, R., \& Mantecón, A. (2018). El auge de la turismofobia chipótesis de investigación o ruido ideológico? Pasos, 16(1), 9-19. https://doi.org/10.25145/j.pasos.2018.16.001

Jansen-Verbeke, M. (1998). Tourismification of historical cities. Annals of Tourism Research, 25(4), 739-742.

Jin, Q., Hu, H., \& Kavan, P. (2016). Factors influencing perceived crowding of tourists and sustainable tourism destination management. Sustainability, 8(10), 976. https://doi.org/10.3390/su8100976

Judd, D.R. (1999). Constructing the tourist bubble. In D.R. Judd \& S. Fainstein (Eds.), The tourist city (pp. 35-53). New Haven - London: Yale University Press.

Judd, D.R. (2003). El turismo urbano y la geografía de la ciudad. Eure, XXIX(87), 51-62. Retrieved from https://scielo.conicyt.cl/pdf/eure/v29n87/art04.pdf

Judd, D.R. \& Fanstein, S. (1999). The tourist city. New Haven - London: Yale University Press.

Knafou, R. (1996). Turismo e territorio. Por uma abordagem científica do turismo. In A.A.B. Rodrigues (Org.), Turismo e Geografía. Reflexoes teóricas e enfoques regionais (pp. 62-75). Sao Paulo: Editora Hucitec.

Koens, K.; Postma, A., \& Papp, B. (2018). Is overtourism overused? Understanding the impact of tourism in a city context. Sustainability, 10(12), 4384. https://doi.org/10.3390/su10124384

Law, C.M. (1993). Urban tourism: attracting visitors to large cities. London: Mansell Publishing Limited.

Lee, T.J., Li, J., \& Kim, H.-K. (2007). Community residents' perceptions and attitudes towards heritage tourism in a historic city. Tourism and Hospitality Planning \& Development, 4(2), 91109. https://doi.org/10.1080/14790530701554124 
López, L., \& Pazos Otón, M. (2009). La imagen de Santiago de Compostela en el mercado turístico italiano. Cuadernos de Turismo, 24, 6etrieved from https://revistas.um.es/turismo/article/view/92661

López-Gay, A., \& Cócola Gant, A (2016). Cambios demográficos en entornos urbanos bajo presión turística: el caso del barri Gòtic de Barcelona. In J. Domínguez-Mújica \& R. Díaz-Hernández (Eds.), Actas del XV Congreso Nacional de la Población Española (pp. 399-413). Fuerteventura: Asociación de Geógrafos Españoles.

López Palomeque, F. (1995). La estrategia del turismo metropolitano: el caso de Barcelona. Estudios Turísticos, 126, 119-142.

Lopez Palomeque, F. (2015). Barcelona, de ciudad con turismo a ciudad turística. Notas sobre un proceso complejo e inacabado. Documents d'anàlisi geográfica, 61(3), 483506. https://doi.org/10.5565/rev/dag.296

Maitland, R. (2010). Everyday life as a creative experience in cities. International Journal of Culture, Tourism and Hospitality Research, 4(3), 176-85. https://doi.org/10.1108/17506181011067574

Maitland, R., \& Newman, P. (2004). Developing metropolitan tourism on the fringe of central London. International Journal of Tourism Research, 6(5), 339-48. https://doi.org/10.1002/jtr.496

Manero Miguel, F. (2011). Patrimonio cultural y transformación urbana: ordenación espacial y proyección turística de los yacimientos arqueopaleontológicos de Atapuerca (Burgos). Cuadernos de Turismo, 27, 617-640. Retrieved from https://revistas.um.es/turismo/article/view/140131

Mansilla López, J.A. (2018). Vecinos en peligro de extinción. Turismo urbano, movimientos sociales y exclusión socioespacial en Barcelona. Pasos, 16(2), 279-296.

https://doi.org/10.25145/j.pasos.2018.16.020

Mathieson, A., \& Wall, G. (1982). Tourism: Economic, physical, and social impacts. London - New York: Longman.

Milano, C. (2018a). Overtourism y Turismofobia: Tendencias globales y contextos locales. Barcelona: The OSTELEA School of Tourism \& Hospitality.

Milano, C. (2018b). Overtourism, malestar social y turismofobia. Un debate controvertido. Pasos, 16(3), 511-564. https://doi.org/10.25145/j.pasos.2018.16.041 
Molina Collado, A., Martín-Consuegra, D., Esteban Talaya, A., \& Díaz Sánchez, E. (2007). Segmentación de la demanda turística: un análisis aplicado a un destino de turismo cultural. Revista de Análisis Turístico, 4, 36-48. https://doi.org/10.1234/RAT2011n11

Morell, M. (2009). Fent barri: heritage tourism policy and neighbourhood scaling in Ciutat de Mallorca. Etnográfica, 13(2), 343-372. Retrieved from

hittps://journals.openedition.org/etnografica/1136

Neuts, B. (2016). An econometric approach to crowding in touristic city centres: Evaluating the utility effect on local residents. Tourism Economics, 22(5), 1055-1074.

https://doi.org/10.5367/te.2015.0477

Neuts, B., \& Nijkamp, P. (2012). Tourist crowding perception and acceptability in cities: An Applied Modelling Study on Bruges. Annals of Tourism Research, 39(4), 21332153. https://doi.org/10.1016/j.annals.2012.07.016.

Neuts, B., Nijkamp, P., \& Van Leeuwen, E. (2012). Crowding externalities from tourist use of urban space. Tourism Economics, 18(3), 649-670. https://doi.org/10.5367/te.2012.0130

Ortega Martínez, E., \& Such Devesa, M.J. (2013). Comunicación y conocimiento del Patrimonio Mundial de la Comunidad de Madrid. Cuadernos de Turismo, 31, 263-288. Retrieved from https://revistas.um.es/turismo/article/view/170871

Quaglieri Domínguez, A., \& Russo, A.P. (2010). Paisajes urbanos en la época post-turística. Propuesta de un marco analítico. Scripta Nova, XIV(323). Retrieved from http://www.ub.edu/geocrit/sn/sn323.htm

Page, S. (1995). Urban tourism. London - New York: Routledge.

Pearce, D. (1998). Tourist districts in Paris: structure and functions. Tourism Management, 19(1), 4965. https://doi.org/10.1016/S0261-5177(97)00095-2

Pearce, D. (1999). Tourism in Paris: studies at the microscale. Annals of Tourism Research, 26(1), 7797. https://doi.org/10.1016/S0160-7383(98)00051-6

Pearce, D. (2001). An integrative framework for urban tourism research. Annals of Tourism Research, 28(4), 926-946. https://doi.org/10.1016/S0160-7383(00)00082-7

Peeters, P., Gössling, S., Klijs, J., Milano, C., Novelli, M., Dijkkmans, C., ... \& Postma, A. (2018). Research for TRAN Committee - Overtourism: impact and possible policy responses. Brussels: European 
Parliament, Directorate General for Internal Policies, Policy Department B: Structural and Cohesion Policies, Transport and Tourism. https://doi.org/10.2861/919195

Popp, M. (2012). Positive and negative urban tourist crowding: Florence, Italy. Tourism Geographies, 14(1), 50-72., https://doi.org/10.1080/14616688.2011.597421

Postma, A., \& Schmuecker, D. (2017). Understanding and overcoming negative impacts of tourism in city destinations: conceptual model and strategic framework. Journal of Tourism Futures, 3(2), 144156 https://doi.org/10.1108/JTF-04-2017-0022

Richards, G. (2017). The new geographies of tourism: Space, place and locality. In D. Dredge and S.Gyimóthy (Eds.) Tourism and Collaborative Consumption: Perspectives, Politics, Policies and Prospects (pp. 169-184). Springer.

Riganti, P., \& Nijkamp, P. (2008). Congestion in popular tourist areas: a multi-attribute experimental choice analysis of willingness-to-wait in Amsterdam. Tourism Economics, 14(1), 2544. https://doi.org/10.5367/000000008783554785

Romero Renau, L. (2018). Touristification, sharing economies and the new geography of urban conflicts. Urban Science, 2(4), 104. https://doi.org/10.3390/urbansci2040104

Russo, A.P. (2002). The "vicious circle" of tourism development in heritage cities. Annals of Tourism Research, 29(1), 165-182. https://doi.org/10.1016/S0160-7383(01)00029-9

Salas-Olmedo, H., Moya-Gómez, B., García-Palomares, J.C., \& Gutiérrez, J. (2018). Tourists' digital footprint in cities: comparing big data sources. Tourism Management, 66, 1325. https://doi.org/10.1016/j.tourman.2017.11.001

Santos Solla, X., \& Pena Cabrera, L. (2014). Management of tourist flows. The Cathedral of Santiago de Compostela. Pasos, 12(4), 719-735. https://doi.org/10.25145/j.pasos.2014.12.052

Sequera, J., \& Nofre, J. (2018). Debates Shaken, not stirred. New debates on touristification and the limits of gentrification. City, 22(5-6). https://doi.org/10.1080/13604813.2018.1548819

Seraphina, H., Sheeranb, P., \& Pilatoc, M. (2018). Over-tourism and the fall of Venice as a destination. Journal of Destination Marketing \& Management, 9, 374376. https://doi.org/10.1016/j.jdmm.2018.01.011

Sorando, D., \& Ardura, A. (2018). Procesos y dinámicas de gentrificación en las ciudades españolas. Papers. Regió Metropolitana de Barcelona. Territori, estratègies, planejament, 60, 35-47. Retrieved from https://www.raco.cat/index.php/PapersIERMB/article/view/339239/430199 
Shoval, N., \& Isaacson, M. (2007). Tracking tourists in the digital age. Annals of Tourism Research, 34(1), 141-159. https://doi.org/10.1016/j.annals.2006.07.007

Stors, N., \& Kagermeier, A. (2013). Crossing the border of the tourist bubble: Touristification in Copenhagen. In T. Thimm (Hrsg.), Tourismus und grenzen (pp. 115-131). Mannheim.

Testa, S. (2011). E le chiamano navi. Il crocerismo fa boom in Laguna. Venice: Corte del Fontego editore.

Trancoso-González, A. (2018). Venice: the problem of overtourism and the impact of cruises. Journal of Regional Research, Investigaciones Regionales, 42, 35-51. Retrieved from hitps://investigacionesregionales.org/wp-content/uploads/sites/3/2019/01/03-

\section{TRANCOSO.pdf}

Troitiño Vinuesa, M.A. (1995). El turismo en las ciudades históricas. Polígonos, 5, 4965. http://dx.doi.org/10.18002/pol.v0i5

Troitiño Vinuesa, M.A. (1998). Turismo y desarrollo sostenible en ciudades históricas. Ería, 47, 211227. https://doi.org/10.17811/er.0.1998.211-227

Troitiño Vinuesa, M.A., \& Troitiño Torralba, L. (2009). Turismo y patrimonio en Castilla y León: las Ciudades Patrimonio de la Humanidad (Ávila, Salamanca y Segovia) como destinos turísticos de referencia. Polígonos, 19, 145 -178. http://dx.doi.org/10.18002/pol.v0i19

Troitiño Vinuesa, M. A., \& Troitiño Torralba, L. (2018). Turismo y dinámicas urbanas: el área central de Madrid. Revista Ábaco, 4(98).

Valenzuela Rubio, M. (1992). Turismo y gran ciudad, una opción de futuro para las metrópolis postindustriales. Revista valenciana d'estudis autonòmics, 13, 103-138.

Valenzuela Rubio, M. (1999). Turismo cultural y políticas urbanas sostenibles en el casco histórico de Madrid. Madrid: Revista de arte, geografía e historia, 2, 387-420.

Van der Borg, J., Costa, P., \& Gotti, G. (1996). Tourism in European heritage cities. Annals of Tourism Research, 23, 306-321. http://dx.doi.org/10.1016/0160-7383(95)00065-8

WTO, World Tourism Organization (2012). Global Report on City Tourism - Cities 2012 Project (AM Report n 6). Madrid: UNWTO.

WTO, World Tourism Organization (2018). 'Overtourism'? - Understanding and Managing Urban Tourism Growth beyond Perceptions. Madrid: UNWTO. https://doi.org/10.18111/9789284419999 
WTO, World Tourism Organization (2019). 'Overtourism'? - Understanding and Managing Urban Tourism Growth beyond Perceptions, Volume 2: Case Studies. Madrid: UNWTO. https://doi.org/10.18111/9789284420629

World Travel \& Tourism Council (2017). Coping with Success: Managing Overcrowding in Tourism Destinations. London: World Travel \& Tourism Council.

Yrigoy, I. (2018). Rent gap reloaded: Airbnb and the shift from residential to touristic rental housing in the Palma Old Quarter in Mallorca, Spain. Urban Studies. https://doi.org/10.1177/0042098018803261

Zárate Martín, M.A. (1995). Imagen y potencial turístico de un Centro Histórico singular, Toledo. In M. Valenzuela Rubio (Coord.), Los turismos de interior (pp. 289-304). Madrid: Ed. Universidad Autónoma de Madrid.

Zárate Martín, M.A. (2007). Estrategias y prácticas turísticas en una Ciudad Patrimonio de la Humanidad, Toledo. Geographicalia, 51, 81-106.

https://doi.org/10.26754/ojs_geoph/geoph.2007511115

Zárate Martín, M.A. (2012). Paisaje, forma y turismo en ciudades históricas. Estudios Geográficos, LXXIII, 273, 657-694. hitps://doi.org/10.3989/egeogr.2012.i273

Zoido Naranjo, F. (2012). Paisaje urbano. Aportaciones para la definición de un marco teórico, conceptual y metodológico. In C. Delgado, J. Juaristi \& S. Tomé (Eds.), Ciudades y paisajes urbanos en el siglo XXI (pp. 13-92). Santander: Ediciones Estudio. 